\title{
Emprendedorismo y políticas públicas. Una introducción a la literatura
}

Entrepreneurship and public policies. An introduction to the literature

Ignacio E. Carballo

Docente Pontificia Universidad Católica

Buenos Aires (UBA), Megister por

Universidad Autónoma de Madrid

y becario doctoral en el Centro de

Estudios de la Estructura Económica

(CENES FCE UBA)

\section{Carlos M. Belloni}

Licenciado en Economia (UBA)

misma universidad. Ejerce la doc

en la UBA y es investigador del

Business School Universidad Austral.

carlosmbelloni@gmilcon

Martín López Amorós

Licenciado en Economía por

Universidad de Buenos Aires (UBA)

Posgrado en Economía en Universidad

Torcuato Di Tella (UTDT) y Maestria

en Economía de la Empresa y Métodos

Madrid (UC3M) . Docente, Unineriad

de Buenos Aires (UBA) Universid

Argentina de la Empresa (UADE)

Universidad Nacional de Tierra del

Fuego (UNTdF) y Universidad

Nacional de Tres de Febrero

mlopezamoros@gmail.con

\section{Resumen}

En este trabajo nos proponemos abordar la temática del emprendedorismo y su relación con las políticas públicas. Para ello, realizamos una revisión introductoria de la literatura partiendo de los principales conceptos que definen el emprendedorismo y las distintas concepciones del emprendedor. Concluimos el trabajo afirmando que los canales que determinan la actividad emprendedora y su relación causal con el desarrollo económico son extensos, generando arduos debates en torno a la efectividad y prácticas adecuadas de las políticas públicas. Es necesario impulsar políticas que comprometan de manera sostenible esfuerzos de los sectores públicos y privados para mantener vigorosos los procesos de emprendedorismo.

Palabras clave: emprendedorismo - políticas públicas - crecimiento - desarrollo económico.

Abstract

In this paper we study entrepreneurship and its relation to public policy through an introductory review of the literature on the main concepts of entrepreneurship and the different conceptions of the entrepreneur. We conclude the paper stating that the channels that determine entrepreneurship and its causal relationship with economic de- 
Eduardo L. Fracchia Ingeniero Industrial y licenciado en Economia, UBA. Director del Área de Economía de IAE Business School de l Universidad Austral.efracchia@iae.edu.a.

\section{Fecha de recepción:}

28.4.2017

velopment are extensive, generating intense debate about the effectiveness and appropriate practices of public policies therein. In this regard we advocate for the promotion of public policies involving sustainable efforts in both public and private sectors to foster strong entrepreneurship processes.

Fecha de aceptación 23.6.2017

Key-words: entrepreneurship - public policies - growth economic development

\section{Introducción}

Durante años se ha vinculado el rol del emprendedor con un conjunto de factores positivos relacionados al crecimiento y desarrollo económico (Baumol, 1986 y 1993; Amoró y Cristi, 2010). Este hecho ha llevado a gobiernos, hacedores de políticas y organismos multilaterales a implementar, a impulsar o recomendar medidas de incentivo y fomento al emprendedorismo.

Así, ya sea bajo una óptica schumpetereana de agente innovador que incrementa la productividad y de esta manera impulsa el crecimiento económico (Winter, 2006; Ravier, 2006; Aghion, Akcigit y Howitt, 2013) o como un actor generador de empleo en vísperas de recesión (Åstebro y Tåg 2015), el emprendedorismo ha logrado ubicarse recientemente en un lugar central dentro de los principales debates de política pública. De igual modo, desde el ámbito académico se han realizado diversos aportes en torno a la importancia del emprendedor en los procesos de crecimiento y desarrollo, su medición y su impacto en distintas variables socioeconómicas.

Históricamente las políticas de fomento al emprendedorismo han sido aquellas destinadas a facilitar o hacer menos costoso el inicio de un nuevo emprendimiento. Sin embargo, en los hechos, no siempre estuvieron ligadas de manera obligada al fomento de nuevas ideas de negocios o innovaciones tecnológicas propiamente dichas. Por el contrario, en muchas ocasiones la implicancia directa fue un fomento a cierto tipo de emprendedores en detrimento de otros.

El debate sobre los incentivos a la creación de nuevos negocios y no nuevos inventos o innovaciones ha ocupado un lugar importante en la literatura.Valiosos aportes se han realizado al respecto del diseño óptimo de una política pública que fomente, no a cualquier tipo de emprendedor, sino al emprendedor innovador (Arrow, 1962; Mansfield, 1991;Acs et al., 2016).
Sin embargo, no todo agente ni toda economía tienen un esquema de incentivos tal que sea conveniente transformarse en emprendedor. Las ganancias potenciales que pueda percibir un empleado en relación de dependencia por saltar al emprendedorismo o ejecutar un plan de negocios están ligadas de manera directa a las decisiones que tome el sector público y al esquema de políticas vigente. De este modo, una arquitectura política inadecuada que no resalte las bondades del autoempleo actuará como limitante para el emprendedorismo en una economía (Astebro, Braunerhjelm y Broström, 2013; Åstebro y Tåg 2015).

El presente trabajo consiste en una revisión bibliográfica introductoria sobre los principales conceptos, debates y desarrollos teóricos en torno a nuestro tema de estudio, la relación emprendedorismo-políticas públicas. Más específicamente, abordamos el rol, la relevancia, las características y los debates abiertos en torno a las políticas públicas como variable de influencia en el emprendedorismo de las distintas economías. De esta manera, el fin último será explorar el por qué de su relevancia en la economía y en la política pública en general.

Con base en ello, en la siguiente sección brindaremos algunos conceptos, definiciones y distinciones sobre los emprendedores y el emprendedorismo. Seguidamente, en la segunda sección, analizaremos la relevancia de las políticas públicas de impulso al emprendedorismo y cómo estas afectan a variables fundamentales de la economía. En el tercer apartado analizaremos los principales determinantes del emprendedorismo identificados en la literatura y su relación con el rol de las políticas públicas de estímulo para luego, en la cuarta sección, describir las características más destacadas en dichas políticas públicas de fomento al emprendedorismo.

Posteriormente, en el apartado quinto, abordaremos los desacuerdos y debates abiertos en torno a las políticas mencionadas. Acercándonos al final del trabajo, en el sexto inciso describiremos metodologías y abordajes para la medición del emprendedorismo y en el séptimo apartado esbozaremos brevemente la situación actual del emprendedorismo a nivel global y, en particular, en América Latina. Finalmente, realizaremos unos comentarios finales a modo de conclusión.

\section{Emprendedorismo y tipos de emprendedores}

Cualquier política de fomento al emprendedorismo nace con una definición clara de su objeto, el emprendedor. Como adelantamos en la introducción, las teorías que brindan al emprendedor un valor fundamental en los procesos de crecimiento y desarrollo económico no son pocas ni similares.

Desde que el emprendedor entró en escena como potencial agente de innovación, con la cualidad de desplazar la frontera de posibilidades de producción de una economía, 
los posturas en torno a los distintos tipos de emprendedores y cuáles son funcionales a dicho desplazamiento no tardaron en llegar. Según Hebert y Link (1988), el concepto del emprendedorismo se introduce y reconoce por primera vez en la obra "Essai sur la nature du commerce" de Richard Cantillon (1680-1734). Allí se define al emprendedor como aquel individuo que asume los riesgos en condiciones de incertidumbre. Con posterioridad, otro de los primeros grandes avances fue el realizado por Jean-Baptiste Say (1767-1832), quien afirmaba que el empresario representaba el catalizador para el desarrollo de productos, que era un trabajador superior (Hoselitz, 1960).

Aunque la teoría económica clásica trató el tema del emprendedor desde muy temprano, no pareció existir un consenso claro y generalizado sobre su definición. Si quisiésemos hablar de una tipología, se podría definir al emprendedor de manera muy general como aquel individuo que cumple con una o dos de las siguientes características: tomador de riesgo, trabajador superior, trabajador inteligente, e innovador (Rodríguez y Jiménez, 2005).

De igual manera, a partir los modelos neoclásicos más tradicionales con base en mercados perfectamente competitivos, el emprendedor ocupó un lugar central. Dicho protagonismo se hacía presente en el momento de satisfacer los excesos de demanda que pudiesen surgir por diversos shocks en la economía. Esto es, frente a un incremento de la demanda en el corto plazo, el ingreso de nuevos oferentes subsanaría el faltante de productos en dicho mercado. Esos oferentes que ingresan al negocio para brindar nueva producción son en los hechos empresarios o emprendedores (Kirzner, 1973; Leibenstein, 1968).

Sin embargo, como afirman Acs y Etro (2009), en dichos modelos no se distinguía en absoluto si la nueva oferta la cubría un empresario individual, un establecimiento, una pequeña empresa o una corporación. Además, en dicha descripción el ingreso de nuevos oferentes en competencia no introduce nuevos productos, nuevo conocimiento o nuevas técnicas de producción. En otras palabras, no se crean nuevos mercados. Esto son los emprendedores que Acs, Åstebro, Audretsch y Robinson (2016) optaron por denominar empresarios o emprendedores de rutina (Acs y Etro, 2009; Acs et al, 2016).

Por otro lado, Schumpeter (1928) introduce en la teoría neoclásica una figura diferente del emprendedor. En su artículo "Unternehmer", 1 denota la figura del emprendedor cuyas decisiones en torno a qué cantidades producir y a qué precio venderlas en el mercado eran trascendentales para impulsar la dinámica de la competencia. Para el autor, el emprendedor es un agente fundamental en la economía, pues es quien transforma ideas en rentabilidad a través de la innovación o la creación de nuevas estrategias de negocio (Palomeque, 2002).

De este modo, a diferencia de sus predecesores de rutina, el empresario o emprendedor schumpeteriano introduce algo al mercado que no existe con antelación. Por definición, este tipo de emprendedor se desenvuelve en mercados imperfectos, creando sus pro- pios mercados mediante la innovación. El emprendedor a la Schumpeter completa deficiencias de mercado o crea demandas que no se sabía que estaban insatisfechas. En el largo plazo, es el emprendedor con estas características el que impulsa efectivamente las fronteras de posibilidades de producción y, en definitiva, el crecimiento y desarrollo económico (Winter, 2006; Ravier, 2006; Aghion, Akcigit y Howitt, 2013).

Otro referente en la literatura es Israel Kirzner, quien amplió el rol del emprendedor á la Schumpeter vinculándolo no solamente con la innovación sino también con la coordinación del mercado, el interés y la naturaleza del capital. El autor centró sus abordajes en los peligros y consecuencias que una regulación podría generar en la libertad individual de los agentes, limitando la capacidad de emprender o, en sus propias palabras, condicionando la "creatividad que mejora la condición humana". De manera general, el emprendedor para Kirzner debe anticiparse a los cambios en las condicione de los mercados y posee una característica natural que no puede cuantificarse. Según el autor, en toda acción humana está presente un elemento que, aunque es crucial en toda actividad optimizadora, no se puede analizar en términos de maximización o con los criterios tradicionales de eficiencia (Kirzner, 1986).

A este tipo de emprendedor Kirzner lo denomina empresario puro. Este es un agente que toma decisiones que provienen de las oportunidades ocultas en los mercados. A diferencia del emprendedor schumpeteriano, la principal virtud del emprendedor no es la capacidad de introducir nuevos productos o procesos de producción, sino la de hallar nuevas oportunidades de negocios que otros agentes no han advertido (Kirzner, 1986).

En consecuencia, una política pública que impulse emprendedores de rutina o schumpeterianos y puros, diferirá en varios aspectos y tendrá resultados diversos. Robert E Litan, William Baumol y Carl Schramm (2008) afirman que el fomento al segundo grupo de emprendedores (á la Schumpeter o Kirzner) es impensado sin intervenciones de políticas estatales que generen un ambiente institucional apropiado (Litan et al, 2008).

Sin embargo, más allá de la primacía que supo obtener el emprendedor innovador o creador de mercados en la literatura, los emprendedores de rutina han sido beneficiados por la política pública en muchas ocasiones. Principalmente en vísperas de recesión y por ser particularmente funcionales a la política económica mediante la generación de empleo.

Asimismo, la generación de empleo con o sin innovación (y desplazamiento de la frontera de producción) han sido dos objetivos que caracterizaron de manera diferente al tipo de políticas públicas de fomento a emprendedores. No obstante, dicha distinción pareciera haber perdido cierta relevancia frente a la creciente masa de personas desempleadas en el mundo y la urgente necesidad de brindar respuestas laborales inmediatas por parte de los gobiernos. Siguiendo esta línea, el Instituto de Emprendedorismo Global y Desarrollo (GEDI, por 
sus siglas en inglés) afirma que la economía mundial enfrentará importantes desafios de mediano y largo plazo destacando entre los más relevantes la necesidad de incrementar la productividad para sostener los estándares de vida presentes. Adelanta también que el crecimiento poblacional incorporará para el año 2050 a más de dos billones de jóvenes adultos a la economía mundial. Estamos en medio de un auge de la fuerza de trabajo que probablemente no finalice por otros 30 o 40 años, por lo cual la generación de puestos de trabajo es la mayor necesidad en el futuro inmediato (Acs, Szerb y Autio, 2016).

En conclusión, ya sean empresarios rutinarios, schumpeterianos o puros, el emprendedorismo per se tiene la facultad de fomentar el empleo. Esto es, aunque fuese mediante el auto-empleo, la micro, pequeña o mediana empresa, el impacto en el mercado de trabajo es directo independientemente de que exista o no innovación y creación de nuevos mercados. Por este motivo, y aunque sólo fuera para incluir agentes desempleados en el mercado laboral, las políticas públicas de impulso al emprendedorismo han cobrado vital relevancia en los últimos años.

A continuación describiremos con mayor profundidad los desarrollos teóricos que justifican la implementación de políticas públicas vinculadas al emprendedorismo en la literatura en la literatura específica. Como veremos, existen fuertes incentivos teóricos para que los gobiernos implementen políticas activas de estímulo al emprendedorismo.

\section{Justificación e impacto de las políticas públicas de emprendedorismo}

La conveniencia o no de que los gobiernos lleven adelante políticas de estímulo emprendedor o (para hablar en términos más amplios) políticas de estímulo productivo, ha sido históricamente una cuestión de debate.

En ese sentido, como señalan Audretsch y Fornielles (2007), el mainstream de la teoría económica sólo acepta la intervención estatal en forma de políticas de estímulo a la producción ante casos de fallas de mercado. Esto es, ante la presencia de economías de escala, asimetrías informativas o externalidades.

Según esta línea de pensamiento, la intervención estatal debería orientarse a solventar las externalidades negativas al emprendedorismo generadas por fallas de mercado tales como la falta de redes empresariales, la poca fluidez de conocimiento productivo (técnicas de producción, innovaciones, etc.) o el simple desconocimiento sobre los beneficios de ser emprendedor tanto para el agente como para la sociedad en su conjunto (Li et al. 2015; Klepper, 2015).

Sin embargo, en la práctica, los países han mostrado una relación fluctuante en términos de implementación de políticas productivas activas. Por ejemplo, Estados Unidos ha tendido a mostrar un movimiento pendular, reacio a políticas de estímulo a la produc- ción en fases de expansión económica, pero más propenso a éstas durante períodos de desaceleración o contracción del nivel de actividad. Con todo, en los últimos años se ha observado una creciente tendencia hacia la aceptación de las políticas activas de estímulo a la producción en distintas fases del ciclo (Audretsch y Fornielles, 2007).

Como adelantamos anteriormente, dentro del contexto de las políticas productivas, el estímulo al emprendedorismo ha venido ganando peso tanto en el ámbito académico como en el referido a las políticas públicas. Sin embargo, el debate acerca de la relevancia y justificación de su implementación también se hizo presente. Por un lado, autores como William Baumol (1990) no encuentran razones para una intervención de fomento explícito del emprendedorismo desde el sector público. Incluso advierten el riesgo de que un apoyo indiscriminado fomente la incorporación al mercado de empresas ineficientes que, de otro modo, no se hubiesen incorporado (Baumol, 1990). Por el contrario, otros autores identifican de manera crítica a la falta de apoyo público o la existencia de obstáculos de naturaleza administrativa como posibles frenos al emprendedorismo latente (Duckett, 2001; Djankov et al., 2002; Pages et al., 2003).

La necesidad o prescindencia de las políticas públicas reside en identificar los canales a través de los cuales los distintos tipos de políticas estimulan o desalientan la actividad emprendedora. En esta línea, encontramos variables como la regulación, los derechos de propiedad, los estímulos en las primeras etapas del proceso emprendedor (start-ups o microempresas), la cultura de promoción al espíritu empresarial mediante la facilitación de recursos financieros y no financieros (Kreft y Sobel, 2005; Audretsch y Thurik, 2004; Audretsch, Grilo, y Thurik, 2007; Stevenson y Lundström, 2007).

De modo aún más general, referentes como David Audretsch (2003) destacan que la política pública orientada a impulsar la actividad emprendedora puede además crear un círculo virtuoso. Esto es, un contexto en el cual los emprendedores estén conectados en red a otros modelos que pueden ser emulados generando así un efecto aprendizaje o demostración que puede resultar especialmente valioso en zonas con predominio de actividades tradicionales (Audretsch, 2003).

Más allá del debate, las políticas de emprendedorismo orientadas a estimular la formación de nuevas empresas cuenta en la actualidad con un creciente consenso a nivel internacional, tanto académico como político (Angelelli y Prats, 2005). Como dijimos en la sección anterior, este consenso se basa en la evidencia de que el emprendedorismo se encuentra correlacionado de manera positiva con uno de los objetivos fundamentales de la política económica de todo país, el crecimiento y el desarrollo económico.

Se torna necesario entonces describir con mayor detalle el móvil o los canales de transmisión del emprendedorismo al desarrollo. La literatura disponible destaca los siguientes 
vínculos entre el emprendedorismo y el desempeño económico de los países (véase, por ejemplo, Baumol, 1986 y 1993; Stevenson y Lundstron, 2002; Beugelsdijk y Noorderhaven, 2004; Angelelli y Prats, 2005; Keuschnigg y Nielsen, 2006; Martín y Picazo, 2008; Amorós y Cristi, 2010):

a) Impacto del emprendedorismo sobre el crecimiento económico. Existen por un lado efectos directos sobre el crecimiento, generados por las capacidades productivas que las nuevas empresas incorporan a la economía. Además, este efecto se retroalimenta de manera circular siguiendo un estilo similar al descripto por Gunnar Myrdal en su teoría de la "Causalidad Circular Acumulativa". Simplificando, la misma consta de un enfoque multicausal donde se delinean variables y sus respectivos vínculos. La idea detrás del concepto es que un cambio en una variable dará lugar a sucesivos cambios en otras. Estos, a su vez, podrían ser cambios circulares y acumulativos. Circulares porque mediante distintas concatenaciones impactarían nuevamente en nuestra variable inicial.Y acumulativos, porque los impactos podrían persistir en distintas rondas hasta desaparecer (o no) de manera gradual en el tiempo (Myrdal y Sitohang, 1957; Fujita, 2007).

En esta línea, las capacidades productivas que las nuevas empresas incorporan a la economía impactan de manera directa en el crecimiento. Pero también, dicho crecimiento económico genera incentivos para un mayor emprendedorismo. A su vez, esta causalidad circular se ve potenciada mediante impactos indirectos que el emprendedorismo genera sobre el crecimiento económico. Entre los más destacados por la literatura se encuentran:

a. Estímulo a la mayor eficiencia. La mayor competencia -o la amenaza de ello- obliga a las empresas ya establecidas en el mercado a mantener una búsqueda constante de un mayor nivel de eficiencia.

b. Cambio estructural. Las empresas ingresantes al mercado tienden a incorporar prácticas más modernas y eficaces. Ante la necesidad de mantener la competitividad, estas prácticas suelen ser incorporadas por las empresas ya establecidas, generando un efecto imitación positivo para la competitividad de la economía.

c. Innovación. Hay al menos dos canales a través de los cuales el emprendedorismo impulsa la innovación. Por un lado, la evidencia sugiere que las empresas nuevas tienen una propensión elevada a la innovación. Por otro lado, la creación de nuevas empresas incrementa la oportunidad de aplicar co- mercialmente conocimientos producidos en ámbitos académicos, lo que mejora los incentivos para su generación (Beugelsdijk y Noorderhaven, 2004).

d. Mayor variedad de productos. El ingreso de nuevos oferentes redunda en una mayor diferenciación de productos, lo que mejora el bienestar de los consumidores, y mejora la competitividad internacional de los países.

b) Impacto sobre el empleo. La evidencia empírica muestra que una porción significativa del empleo es creado por nuevas empresas. Por caso, Reynolds y coautores (2004) encontraron que, en Estados Unidos, la aceleración en la creación de nuevas empresas precede la generación de empleo. Esto quiere decir que el emprendedorismo no genera una simple reasignación del factor trabajo, sino que lleva a una creación neta de empleo (Reynolds et. al, 2004).

El caso de Europa es un claro ejemplo de ello. Muy posiblemente, la mayor consecuencia de la crisis actual es el importante incremento del desempleo. La amplia oferta de jóvenes expulsados del mercado laboral ha impulsado una mayor atención a la capacitación sobre temáticas inherentes al emprendedorismo, asesoría legal al emprendedor, contaduría, cursos de innovación y demás servicios comúnmente brindados por diversas instituciones públicas y privadas. El eje se encuentra en impulsar a dichos jóvenes a transformarse en sus propios jefes llevando adelante microemprendimientos productivos. Esto es, la posibilidad de promover la microempresa y el autoempleo en un contexto de alta desocupación.

Otros autores discrepan con esta posición, y enfatizan sobre la menor calidad del empleo generado por empresas nuevas en contraposición a las empresas ya establecidas (Shane, 2009). De cualquier modo, en la mayor parte de la literatura parecería existir concordancia en la existencia de un vínculo positivo entre empleo y emprendedorismo.

c) Impacto sobre la innovación. Como hemos adelantado, autores como Berríos Lugo y Espina (2014) señalan que las pequeñas empresas juegan un papel importante en los cambios tecnológicos, sirven de agente de cambio y regeneración económica, crean nuevos nichos de mercado y crean empleo. Desde este punto de vista, una alta tasa de emprendedorismo aceleraría las transformaciones económicas, puesto que las nuevas empresas son más propensas a liderar los cambios que las empresas ya establecidas y consolidadas.

A su vez, los resultados empíricos que recoge la literatura económica, permiten afirmar la relación positiva existente entre el dinamismo en la creación de empresas y el crecimiento económico (Reynolds, Hay, Bygrave, Camp y Autio, 1999; Zacharakis, Sheperd y Bygrave, 2000; Balso, 2004). Por ejemplo, de acuerdo con Zacharakis y coautores (2000), el análisis 
realizado sobre 16 países desarrollados les lleva a concluir que aproximadamente la mitad de las diferencias en las tasas de crecimiento económico entre dichos países es atribuible a la actividad emprendedora. Dicho resultado confirma algunas de las conclusiones de los autores sobre el impacto positivo de la creación de empresas en las tasas de crecimiento económico (Zacharakis, et al. 2000).Por su parte, a nivel regional, diversos trabajos han analizado la relación empírica y teórica entre el emprendedorismo y la creación de empleo o la movilidad social (Kantis, Koening, y Angelelli, 2005; Kantis, Federico, y Trajtenberg 2012; Ordeñana y Villa 2012; Martinez, 2016). De manera complementaria, Jason Henderson (2002) muestra que el dinamismo emprendedor no sólo afecta a los niveles de creación de empleo y renta, sino que ayuda a conectar las economías locales con la economía global. En definitiva, y tal como señala Minniti (1999), los emprendedores actúan como catalizadores en la creación de redes y externalidades para la difusión de nuevas ideas. Un ejemplo empírico para el caso argentino puede encontrarse en Bekerman, Wiñazky y Moncaut (2014).

De esta manera, parece claro que hay fuertes incentivos para justificar que los gobiernos desarrollen políticas activas de estímulo al emprendedorismo. Este hecho se condice con la creciente aceptación de tales políticas en la práctica (Audretsch y Fornielles, 2007).

Antes de analizar las características y el diseño de las políticas públicas de estímulo al emprendedor, se torna necesario describir cuáles son las dimensiones del emprendedorismo como variable. La siguiente sección nos ayudará a comprender dichas dimensiones con el fin de poder analizar de manera más clara qué determinantes posee el emprendedorismo y cómo el sector público puede influir en las mismas con su intervención.

\section{Dimensiones y determinantes del emprendedorismo}

Por política pública se conoce al conjunto de medidas ideado por un gobierno determinado que se propone solucionar algún asunto específico. Para esto, primero es necesario definir cuál será el campo de acción del Estado, cómo intervendrá y con qué magnitud (Winchester, 2011).

En este trabajo el campo de acción de las políticas públicas es el emprendedorismo. De modo que antes de avanzar en el cómo y en qué magnitud se realizan las intervenciones óptimas, se torna necesario describir las variables independientes del emprendedorismo. De la literatura se desprende que el emprendedorismo cuenta con un complejo entramado de determinantes cuya importancia y relación es dificil de identificar en la práctica.

Por ejemplo, a nivel regional se han identificado diversos aspectos comunes (como la baja propensión al riesgo, la falta de apoyo sistémico, el nivel educativo, el origen social, la experiencia empresarial, entre otros) que alientan o desalientan la demanda y oferta de nuevas empresas innovadoras (Kantis,Angelelli, y Moori, 2004; Kantis y Drucaroff, 2009; Kantis, 2010).
El capital social y las redes, así como el contexto en sus diversas dimensiones (familiar, socioeconómico, institucional, político y organizacional) son elementos fundamentales en el diseño y éxito de toda política pública, abordados ampliamente en la literatura (Ferri, Deakins y Whittam, 2009; Bratkovic, Antoncic y Ruzzier, 2009; Schött 2011; Arellano, 2016; entre tantos otros). Siguiendo a Berríos Lugo y Espina (2014), podemos diferenciar tres grandes grupos de influencia:

a) Determinantes institucionales. Esto incluye a las políticas gubernamentales específicas y a los programas gubernamentales en general (entre los que se incluye, por ejemplo, la política macroeconómica).

Este contexto institucional se construye a través de leyes y demás elementos normativos, específicamente vinculados al emprendedorismo, o que lo afecten de manera indirecta. La corrupción, por ejemplo, también es un elemento distintivo, en este caso negativo, puesto que reduce el atractivo del emprendedorismo al incrementar los costos percibidos por los potenciales emprendedores (Martín y Picazo, 2008).

b) Determinantes económicos. Aparecen aquí elementos como la disponibilidad de capital financiero, la inversión en I+D, la infraestructura comercial y profesional, y la disponibilidad o calidad de la infraestructura fisica. A estos factores hay que sumar elementos como la distribución del ingreso -hay evidencia de que sociedades menos equitativas son también menos emprendedoras-, ingreso per cápita, las tasas de interés y el ritmo de crecimiento de la economía. También el apropiado funcionamiento de los mercados de factores productivos es de central importancia para el desarrollo de un ambiente favorable al emprendedorismo.

c) Determinantes sociales. El contexto cultural y educativo son elementos fuertemente condicionantes del nivel de emprendedorismo de los países. Esto incluye también cuestiones como las relaciones sociales de los potenciales emprendedores, la valoración social del emprendedorismo, la tolerancia social al fracaso y la existencia de modelos empresariales ejemplares. El apoyo a la mujer también aparece entre los aspectos mencionados.

Al igual que los impactos analizados en el apartado anterior, estos determinantes no son independientes. En su estudio, Berríos Lugo y Espina (2014) analizan la correlación entre estas tres dimensiones, encontrando una relación positiva entre ellos. Sin embargo, esta relación es moderada, lo que implica que la mejora en una dimensión no necesariamente derrama en las otras, al menos no en un nivel deseable.

En consecuencia, la evidencia indica que es preciso que las políticas públicas de estímulo al emprendedorismo actúen, de manera directa, sobre los tres grupos de determinantes. De igual modo, los tres grupos de determinantes refieren a la arquitectura de incentivos 
mencionada anteriormente en este trabajo. Así, instituciones que puedan desarrollarse en torno al emprendedorismo se tornan de vital importancia. Éstas influyen de modo decisivo en los incentivos reduciendo la incertidumbre, los costos de transacción y facilitando la coordinación entre agentes.

Retomando a Kirzner, otro determinante del emprendedorismo es la capacidad de reconocimiento de oportunidades de mercado. Dicho reconocimiento constituye la razón de ser del mencionado emprendedor puro. Por lo tanto, conocer el proceso de descubrimiento de una oportunidad que realizan los emprendedores es otro aspecto fundamental para el diseño de las políticas de fomento.

Pero reconocer dichas oportunidades no es tarea fácil. De hecho, el eje de la cuestión es que no se sabe ex-ante qué es lo que se busca. De saberse, habría sido el mercado mismo a través del arbitraje quien ocuparía el vacío. Es por estos motivos que se concluye la imposibilidad de impulsar el procedimiento de búsqueda mediante la racionalidad económica tradicional que opera en base a un cálculo costo-beneficio (comparando los costos inherentes a la investigación de información con los beneficios potenciales por la obtención de una información más precisa). El hallazgo de nuevas oportunidades no puede darse más que de manera aleatoria y espontánea, y se vincula de manera directa con la capacidad del emprendedor (Chabaud y Ngijol, 2004).

Otros autores recomiendan pensar la oportunidad empresarial como un fenómeno social (Jiménez y Rodriguez, 2005). Bajo esta óptica, el análisis del emprendedorismo se enmarca dentro de la relación entre el emprendedor y su proyecto (Bruyat, 1993; Fayolle, 2000) que a su vez no puede desprenderse del contexto relacional (Hills et al., 1997; Koller, 1998). De igual modo, influye en el emprendedor su inserción social en redes que le permitirán discutir, probar o ajustar su proyecto, así como obtener recursos y/o información relevante (Burt, 1992), de modo que la dinámica de intercambios conduzca al emprendedor y a sus redes a la validación de la oportunidad de emprendimiento.

Didier Chabaud y Joseph Ngijol (2004) desarrollaron el siguiente cuadro conceptual que muestra las tres dimensiones a través de las cuales se construye la oportunidad empresarial: el individuo, su inserción en la red social y la naturaleza del proyecto (Chabaud y Ngijol, 2004). Se observa que el apoyo gubernamental mediante políticas públicas de emprendedorismo es fundamental para mejorar la inserción social facilitando la creación de oportunidades.
Esquema 1 - La construcción de oportunidades

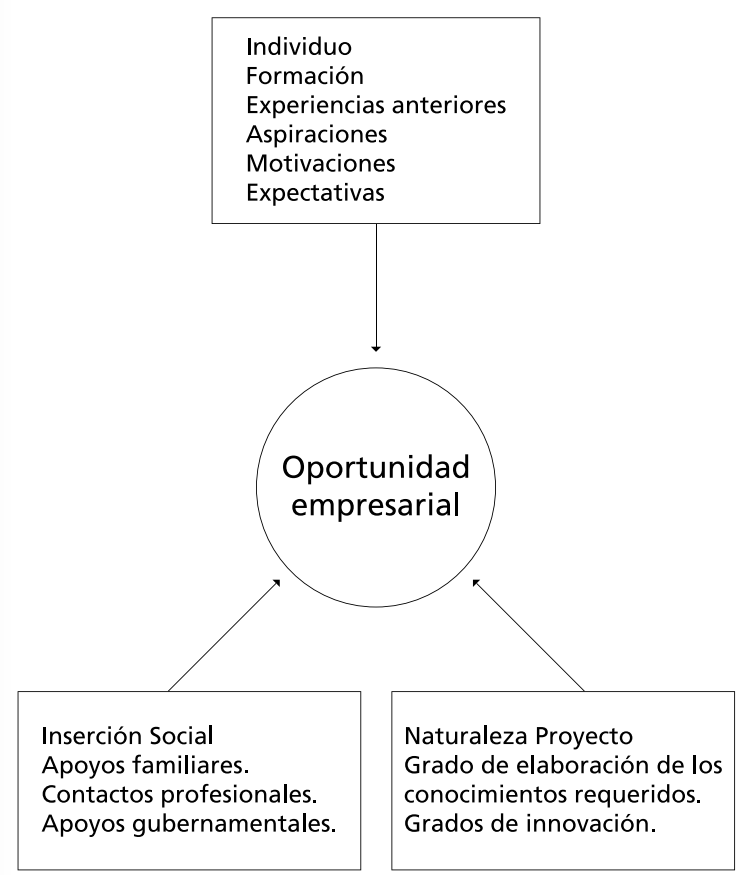

Fuente: Chabaud y Ngijol (2004, p. 16)

En resumen, encontramos que variables institucionales, económicas y sociales, determinan el factor emprendedor en las economías. Cuando hablamos de emprendedores innovadores, la capacidad de reconocer oportunidades de mercado se traduce como una de las determinantes más importantes.

Habiendo introducido al emprendedor, señalando los canales teóricos a través de los cuales el emprendedorismo influye en la economía, y abordado sus principales determinantes, podemos avanzar en describir cómo debe ser, según nuestra revisión bibliográfica, una política pública efectiva de estímulo al emprendedorismo. Para ello, describiremos a continuación las principales características y recomendaciones que se encuentra en esas fuentes.

\section{Características y recomendaciones para una política de emprendedorismo}

La literatura disponible plantea diferentes tipos de políticas públicas orientadas a fomentar el emprendedorismo. Una posibilidad es pensar que el diseño de las políticas públicas gira en torno a los siguientes ejes propuestos por diversos autores -ejes que no son mutuamente excluyentes (Kantis, 2004; Angelelli y Prats, 2005; Audretsch y Fornielles, 2007): 
a) Políticas horizontales o verticales. Esta disyuntiva se refiere al diseño e implementación de políticas que estimulen el emprendedorismo a lo ancho de toda la estructura económica del país, en contraposición con el fomento del emprendedorismo en sectores específicos, en principio identificados por contar con un elevado potencial de crecimiento. Berríos Lugo y Espina (2014) refieren a estos tipos de política como "facilitativas" y "directivas". En cualquier caso, como señala Kantis (2004), es común que en un programa de estímulo al emprendedorismo coexistan ambos enfoques.

b) Políticas de provisión de recursos financieros o de mejora del contexto. El conjunto de estas iniciativas responde a una orientación común: la puesta a disposición de recursos para la innovación a potenciales emprendedores. Las políticas de estímulo al emprendedorismo suelen tener un componente de apoyo financiero (subsidios, beneficios fiscales y créditos blandos, por ejemplo). En diversos países europeos, por ejemplo, los estímulos financieros al emprendedorismo se presentan como una herramienta generadora de empleo y compensadora de los gastos inherentes al Estado de Bienestar. Sin embargo, la mejora de elementos contextuales -procesos de creación de empresas, oferta de capital humano o redes de colaboración, entre otrostambién es un elemento de mucha importancia.

Más allá de estas divisiones conceptuales, en términos genéricos, otros autores plantean que toda política exitosa de estímulo debe contener las siguientes características (Angelelli y Prats 2005; Hidalgo et al., 2014):

a) Buscar el fortalecimiento y articulación de los actores locales. El concepto de red es fundamental para estimular el emprendedorismo.

b) Contar con la participación de los actores locales involucrados en el proceso de creación de empresas. El emprendedorismo es ante todo fenómeno local, por lo que es indispensable que los actores locales se compro- metan con los programas de estímulo. Esto facilita además la incorporación a las políticas públicas de un factor importante, como es la heterogeneidad regional (Romero Luna y Fernández Serrano, 2007).

c) Permitir la generación de mecanismos sostenibles de prestación de servicios a los emprendedores. Las políticas aisladas y/o insostenibles en el tiempo pierden efectividad, al lograr incentivos menos atractivos para los potenciales emprendedores.

d) Partir de una combinación adecuada de servicios financieros y no financieros. Aunque al apoyo financiero es importante, no es suficiente. De igual manera, un contexto adecuado puede ser insuficiente si no se accede al capital financiero necesario para materializar la creación de nuevas empresas.

e) Evaluar los resultados para ir mejorando la estrategia. La importancia de la evaluación en las políticas públicas en general ha sido tratada con amplitud (Pignatta, 2016). El desarrollo de políticas públicas de estímulo al emprendedorismo no es estático. Es preciso que sus resultados sean evaluados de manera continua para disponer, a partir de esta evaluación, las modificaciones que sean necesarias. Las políticas de emprendedorismo -como en general las políticas productivasdeben ser pensadas como un conjunto de normas e instrumentos en continua reelaboración.

Desde otras perspectivas, algunos autores plantean que la motivación y justificación de las políticas de impulso al emprendedorismo provienen de las características inherentes al contexto de la economía. En esta línea, Acs, Åstebro, Audretsch y Robinson (2016) plantean tres características centrales que deben estar presentes en la economía donde se aplicará la política en cuestión (también Acs y Etro, 2009):

a) Mayor beneficio al emprendedor. Debe existir un amplio número de personas trabajando en empresas establecidas, que estarían mejor haciéndolo por cuenta propia. Esto es, debe existir talento empresarial en las personas con trabajos asalariados. 
b) Mayor beneficio social de primar el emprendedorismo. Como sociedad, se debe estar en peores condiciones debido a la mencionada existencia de un amplio número de personas con potencial emprendedor trabajando en empresas establecidas. En otras palabras, la economía debería estar en una peor situación como resultado del talento empresarial no implementado.

c) Capacidad política. Debe existir la capacidad de intervención política para mejorar este problema social.

Existe amplio consenso en la necesidad de que las políticas de estímulo presenten, a grandes rasgos, las dimensiones mencionadas anteriormente. De igual modo, hay consenso en la necesidad de que una política exitosa de estímulo debe contar con la participación de los siguientes actores (Chirinos, 2013; Gómez y Mitchell, 2014):

a) El Estado. Diversos académicos han destacado las relaciones entre el Estado y los empresarios como un vínculo fundamental para el desarrollo económico (Schneider y Wolfson, 1999; Schott y Jensen, 2008). A través de leyes de estímulo, proveyendo los lineamientos financieros y estableciendo mecanismos de información y comunicación. Se entiende al Estado en un sentido amplio, incorporando todos los niveles de gobierno, y las instituciones públicas vinculadas con la creación y desarrollo de empresas.

b) Las instituciones educativas. Mediante la incorporación de carreras vinculadas al emprendedorismo, incentivando el espíritu emprendedor, proveyendo conocimiento, reforzando la capacidad de innovación y conectándose con el sector productivo (véase Kantis, Postigo y Tamborini, 2002 para un ejemplo empírico del caso argentino).

c) Las empresas públicas y privadas. Brindando asistencia a empresas nacientes, explotando las complementariedades e intercambiando estrategias de negocio.
Esta estructura tipo de las políticas de estímulo al emprendedorismo se resume en el Esquema 2.

\section{Esquema 2 - Recursos necesarios para el emprendedorismo}

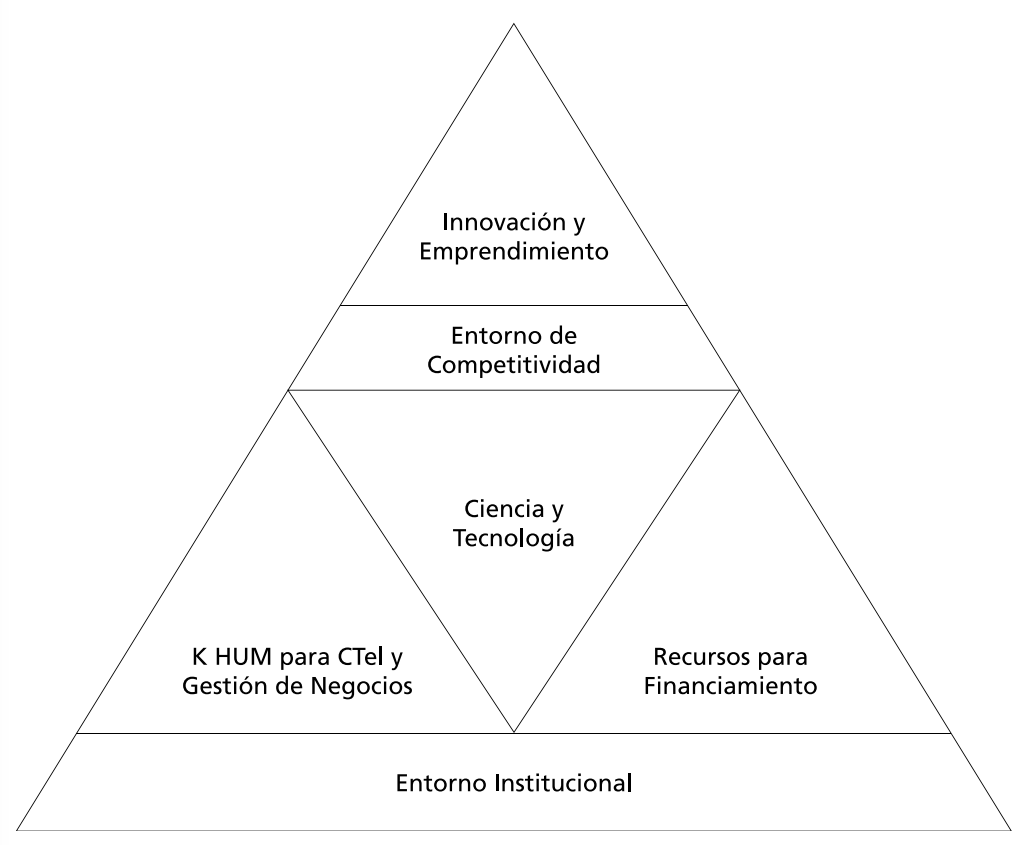

Fuente: Gómez y Mitchell (2014)

De acuerdo con este esquema, el pilar básico del emprendedorismo es un entorno institucional apropiado. A ello se le deben sumar una serie de recursos tales como el capital humano, la ciencia y la tecnología, y los recursos financieros. Sobre esa base se debe construir un entorno competitivo que fomente la innovación y el emprendedorismo, como dos fuerzas que se retroalimenten.

Vale aclarar que, aunque esta es la visión más difundida en la literatura (es decir, el entorno institucional como pilar básico sobre el que se acumulan los otros recursos necesarios para el emprendedorismo), su adopción no es unánime. Otros autores como por ejemplo Hall y Sobell (2006) plantean en su análisis una lógica diferente, en la que el entorno institucional determina la vinculación entre recursos (economic inputs and resources) y resultados (entrepreneurial outcomes). Evidentemente, el orden de causalidad tiene impacto sobre el diseño de las políticas públicas (Hall y Sobell. 2006).

En torno a estos recursos necesarios pueden ordenarse las recomendaciones habituales para el desarrollo de políticas públicas efectivas orientadas al impulso del emprendedorismo. 


\section{4.a Mejora del entorno institucional}

Las políticas dirigidas a mejorar el entorno institucional en el que se desarrollan las iniciativas empresariales vienen adquiriendo cada vez mayor importancia en el diseño de las políticas públicas debido a que constituyen un resorte fundamental para reforzar las capacidades de crear y aprovechar ventajas competitivas (Gregersen y Johnson, 1997; Belussi, Gottardi y Rullani, 2004). Dentro de este eje, la literatura disponible ofrece una variedad de propuestas. Aunque suelen estar sesgadas por los casos concretos de análisis, las propuestas muestran elementos en común (Angelelli y Prats, 2005; Gómez y Mitchell, 2014; Berríos Lugo y Espina, 2014). Las más generalizadas son:

I. Garantizar los derechos de propiedad. Esta es considerada la primera condición para incentivar el emprendedorismo.

II. Definir y comprometer a las instituciones con un rol concreto en la promoción de políticas a favor del emprendedorismo. Por ejemplo, asignar a un banco público el rol de financiador de emprendimientos de esta naturaleza, y a determinados centros de investigación el rol de coordinadores de la generación de innovación aplicada a la producción.

III. Simplificar los procedimientos para la constitución de nuevas empresas y la gestión de recurso financieros. Hall y Sobell (2006) y Kreft y Sobel (2005) van más allá, planteando que se debe avanzar en una línea clara de reducción de regulación en todos aquellos aspecto vinculados al emprendedorismo, incluyendo al mercado de trabajo y al sistema de seguridad social.

IV. Eliminar barreras a la entrada de nuevas firmas en determinados sectores. En línea con el punto anterior, Henrekson y Stenkula (2009) plantean la importancia de evitar que la regulación genere barreras a la entrada de nuevas firmas en determinados sectores. Regulaciones favorables a los consumidores, por ejemplo, pueden ser costosas en el mediano y largo plazo si el objetivo es estimular el emprendedorismo. Otros trabajos, sin embargo, sostienen que barreras a la entrada demasiado bajas podrían desincentivar la innovación, al reducir la posibilidad de apropiación de los beneficios de la innovación ante la mayor competencia (Rodrik, 2007; Lederman et al. 2014).

V. Revisar las estructuras tributarias. En muchos casos, la estructura tributaria se constituye en un desincentivo a la actividad emprendedora, por ejemplo promoviendo el "enanismo fiscal" de las firmas (se inscriben en niveles menores al que les corresponde por sus ingresos), lo que limita su potencial de crecimiento. Complementariamente, se debe reducir el nivel de evasión fiscal apelando a mejores controles (Henrekson y Stenkula, 2009).
VI. Desarrollo de redes. Crear instituciones dedicadas a la formación de redes entre empresarios, potenciales empresarios, universidades, centros de investigación y otros actores relevantes en el proceso de creación y desarrollo de empresas (Ferri, Deakins y Whittam, 2009; Bratkovic, Antoncic y Ruzzier, 2009; Schött 2011; Bekerman, Wiñazky y Moncaut, 2014).

VII. Reducir riesgos. Reducir el costo del fracaso de los emprendedores, creando un marco legal apropiado para la resolución de las situaciones de insolvencia (Hidalgo et al., 2014).

VIII. Comunicar y difundir correctamente. Mejorar la difusión de los programas de estímulo al emprendedorismo con el objetivo de alcanzar emprendedores potenciales latentes (Observatorio Nacional del Emprendedor, 2015).

IX. Propiciar la ampliación de los mercados. Esto lleva a una menor probabilidad de que las nuevas firmas desplacen a las firmas ya establecidas, lo que a su vez mejora la aceptación de las políticas de estímulo al emprendedorismo.

\section{4.b Recursos financieros}

Aunque debemos señalar que el apoyo no es unánime (véase por ejemplo Henrekson y Stenkula, 2009), según la visión mayoritaria de la literatura, otro elemento central en el impulso a la creación de nuevas empresas es el financiamiento (Kantis, Ishida y Komori, 2002; Studart y Suaznabar, 2004).

La creación de empresas, y probablemente su sostenimiento durante la etapa de desarrollo, requiere recursos difíciles de conseguir por los canales tradicionales, como préstamos de bancos comerciales. De este modo, el crédito bancario formal es una fuente de vital importancia para la financiación de nuevas empresas, no sólo las más pequeñas (Robb y Robinson, 2014). Por ello, la literatura disponible impulsa los siguientes mecanismos de financiamiento como potenciadores del emprendedorismo:

Desarrollo de fondos de capital de riesgo. Este mecanismo tiene como propósito facilitar el acceso de nuevas firmas a los fondos necesarios para su lanzamiento. Autores como Henrekson y Stenkula (2009) y Keuschnigg y Nielsen (2006) dan preponderancia a este esquema por sobre los créditos blandos subsidiados por el Estado porque generan un mejor esquema de premios y castigos para lanzamientos exitosos y no exitosos, respectivamente. En cambio, sí apoyan la asistencia del Estado a estos fondos de capital de riesgo, mediante el aporte de fondos o, preferentemente, proveyendo al sector una estructura fiscal favorable (Henrekson y Stenkula, 2009; Keuschnigg y Nielsen, 2006). Hidalgo et al. (2014) plantean además que el Estado debería asistir a los nuevos fondos de capital de riesgo, ya que estos suelen obtener pérdidas en sus primeros años de vida (Hidalgo et al, 2014). 
a) Estímulo a sistemas de financiamiento alternativos. Algunos ejemplos podrían ser los crecientes esquemas de crowdfunding o los llamados business angels, basados en los aportes de empresarios particulares (Romero Luna y Fernández Serrano, 2007).

b) Provisión de beneficios fiscales. Contempla la implementación de retornos tributarios por inversiones o recorte de impuestos sobre los beneficios durante las fases de desarrollo de las firmas (Keuschnigg y Nielsen, 2006).

c) Desarrollo de esquemas como compras públicas o contratación de servicios. Su objetivo sería garantizar un piso de ingreso a las empresas nacientes. También la administración de aranceles puede financiar, de manera indirecta, a las empresas nuevas, al facilitar su acceso a un mercado protegido (Audretsch y Fornielles, 2007).

\section{4.c Capital Humano y Ciencia y Tecnología}

Otros elementos centrales para el emprendedorismo recurrentemente citados en la literatura son la disponibilidad de capital humano, y la inversión en ciencia y tecnología En ambos casos, la literatura reconoce que hay margen para que las políticas públicas mejoren estos fundamentos del emprendedorismo.

Las principales recomendaciones al respecto son las siguientes:

a) Reorientar los recursos financieros de investigación a sectores vinculados con la producción. Además, estimular la transformación de la innovación en recursos mediante su comercialización. Se considera que la investigación en $\mathrm{I}+\mathrm{D}+\mathrm{i}$ no es suficiente para estimular el emprendedorismo si no se lo conecta con el mundo empresarial (Henrekson y Stenkula, 2009; Audrestch y Phillips, 2007).

b) Reforzar el rol del Estado. Se torna indispensable profundizar el papel coordinador de los organismos públicos vinculados a la ciencia y a la tecnología.

c) Incentivar ciencias estratégicas. Promover un rol más preponderante de las ciencias puras y las ingenierías en la educación superior (Lederman et al, 2014).

d) Impulsar al investigador profesional. Proveer mejores incentivos para aquellos que opten por desarrollar una carrera profesional vinculada a la investigación.

e) Fomentar la educación emprendedora de base. Propiciar la formación del espíritu emprendedor dentro del sistema educativo, estimulando el aprendizaje del tipo "learning by doing" (Hidalgo et al., 2014; Romero Luna y Fernández Serrano, 2007).

f) Fomentar la educación emprendedora a emprendedores. Esto es, complementar el punto anterior con el financiamiento público o privado de programas directos de entrenamiento a emprendedores.

g) Incentivar al extranjero. Atraer capital humano extranjero como medio de apoyo a los proyectos de $\mathrm{I}+\mathrm{D}+\mathrm{i}$.

En este marco, la educación ha ocupado una relevancia fundamental en torno a la literatura sobre desarrollo, innovación y emprendedorismo tanto en la global (Lundvall 1992; Etzkowitz 1998, entre otros) como en la regional (Guerrero y Luna, 1997; Kantis, Postigo y Tamborini, 2002; Peirano, 2005; Albornoz, 2009; Rikap, 2012; Di Meglio, 2016).

En línea con el punto mencionado anteriormente, un autor que ha dedicado especial atención al rol de la investigación y la educación como políticas de estímulo al emprendedorismo es el anteriormente mencionado David Audretsch.

Audretsch ha destacado en diferentes artículos la importancia de que la investigación llevada adelante en las universidades esté conectada con su aplicación comercial. También hemos adelantado los aportes de Kantis y Di Meglio en esta línea. Desde este punto de vista, la investigación y el emprendedorismo son fenómenos que se retroalimentan, ya que el emprendedorismo genera la oportunidad de aplicar comercialmente la innovación, mientras que la investigación en las universidades puede actuar como una incubadora de nuevas empresas (Kantis, Postigo y Tamborini, 2002; Audretsch y Fornielles, 2007; Audrestch y Phillips, 2007; Di Meglio, 2016).

Sin embargo, como señala Callejón (2009), quienes generan el conocimiento no suelen ser quienes lo aplican. Por ello, en lo que se refiere a ciencia y tecnología, Audrestch y Phillips (2007) recomiendan la implementación de políticas que contemplan los siguientes elementos generales: 
a) Fondeo estatal a universidades de investigación. Generando así un impulso directo a la educación en base a investigación aplicada.

b) Creación de una cultura emprendedora dentro de estas universidades. Las universidades deben funcionar como incubadoras de emprendedores. Es importante que los investigadores lleven adelante sus programas de investigación pensando en su posterior aplicación comercial.

c) Apoyo de las universidades estatales al sector privado. Se debe estimular el vínculo de las universidades como prestadores de servicios a los sectores productivos.

De esta manera, la universidad se torna un actor fundamental. La universidad como herramienta de impulso al emprendedorismo tendría una estructura como la señalada en el Esquema 3.

\section{Esquema 3 - La universidad emprendedora}

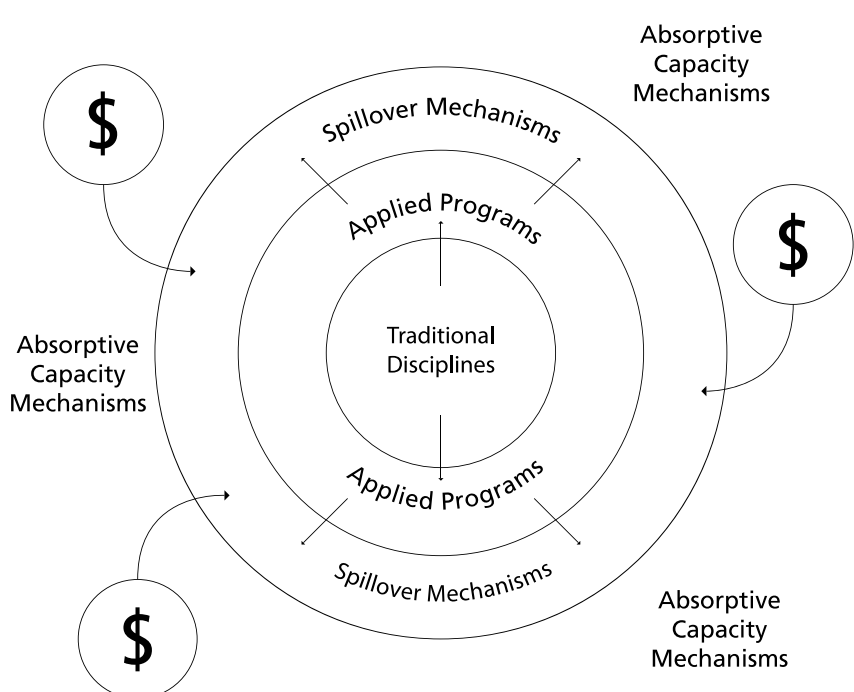

Fuente: Audrestch y Phillips (2007)

El Esquema 3 refleja que las disciplinas tradicionales son sólo el corazón de la universidad. Este núcleo debe coordinarse con programas y actividades de tal modo que generen un conocimiento que luego pueda ser aplicado y transformado en aplicaciones comerciales con valor agregado.
Por último, una característica adicional para contemplar en el diseño de las políticas en pos del emprendedorismo son la descentralización y especificidad de las mismas. Existen diversas razones para asumir que la regionalización de la política de creación de empresas puede suponer ventajas para el logro de una mayor eficiencia de la misma (Verdú y Soriano, 2008).

En primer lugar, debido a la dimensión espacial que suelen tener los procesos de creación de empresas. Estos, en general, están concentrados en entornos territoriales concretos o áreas específicas. En segundo lugar, porque una actuación descentralizada amplía el propio campo de acción de las políticas. En otras palabras, cuando las medidas de promoción del emprendedorismo se focalizan en una determinada región adquieren también un componente instrumental de políticas complementarias, especialmente de desarrollo regional y de innovación. Por último, en tercer lugar, la regionalización sería deseable porque los sistemas regionales de innovación funcionan de forma diversa en zonas distintas.

En cuanto a la especificidad, la consideración de este rasgo en las políticas se basa en la importancia del condicionante que supone la capacidad territorial en términos de conocimiento, especialmente la dotación y calidad de las universidades (Klofsten y JonesEvans, 2000), para el éxito de determinados programas como por ejemplo la promoción de empresas de base tecnológica (high technology new firms) (Asheim y Coenen, 2005; Audretsch y Lehman, 2005).

Sin embargo, algunos autores llegan a conclusiones más matizadas sobre la especificidad de las políticas públicas e incluso, por el contrario, defienden acciones de política de amplio espectro que fomenten la cultura emprendedora en el conjunto de la sociedad (Reynolds, Hay, Bygrave, Camp y Autio, 1999; Howells, 2005).

Hasta ahora hemos abordado y desarrollado las ideas y conceptos más relevantes en torno a nuestro tópico de estudio. Sin embargo, como ya hemos adelantado, nada está totalmente dicho en términos de emprendedorismo y políticas públicas. Antes de describir las herramientas prácticas de cuantificación e inmiscuirnos en el estado actual del emprendedorismo en el mundo y América Latina, se torna necesario brindar algunas líneas a los principales cuestionamientos y reparos en términos de políticas públicas de estímulo al emprendedorismo

\section{Desacuerdos y reparos en torno a las políticas de emprendedorismo}

Como venimos argumentando en las secciones precedentes, aunque existe una creciente aceptación a las políticas de estímulo al emprendedorismo, ésta no es unánime. Los cuestionamientos al respecto de las características que deben tener las políticas de este tipo o la efectiva necesidad de su aplicación no son pocos. 
En este sentido, Audretsch y Fornielles (2007) destacan dos tipos de cuestionamientos hacia las políticas productivas activas. El primero está asociado al riesgo de "elegir ganadores". Experiencias como la de muchos países de América Latina muestran que es muy difícil identificar correctamente a los sectores con elevado potencial competitivo y que merecen, por lo tanto asumir los costos de una política de estímulo al emprendedorismo que beneficie a ese sector.

A esta objeción responden los autores señalando que las políticas activas no deben sustituir al mercado en la elección de los ganadores, sino suplementar o corregir esa elección, asegurando que el desempeño sectorial no se encuentre condicionado por incentivos perversos. De hecho, la mayor parte de las políticas revisadas en la sección anterior se enmarcan dentro de las llamadas políticas horizontales, lo que minimiza e riesgo de la elección incorrecta de potenciales ganadores (Audrestch y Fornielles, 2007).

Otro cuestionamiento tradicional a este tipo de políticas consiste en el potencial riesgo de rent-seeking asociado a los programas que incluyen servicios financieros a las empresas. En esa línea se expresan Hall y Sobell (2006), quienes además cuestionan la efectividad de los programas públicos de asistencia financiera, sosteniendo que la evidencia empírica no muestra que la falta de fondos privados sea un impedimento para el emprendedorismo (Hall y Sobell, 2006).

Al respecto, Audretsch y Fornielles (2007) minimizan el riesgo de rent-seeking, señalando que los estados cuentan actualmente con mecanismos de transparencia lo suficientemente desarrollados como para exponer este tipo de comportamientos por parte de los empresarios, evitando así que éstos puedan ejercer influencia sobre los gobiernos.

En cuanto a la necesidad de fondeo a los emprendedores, Henrekson y Stenkula (2009) plantean una visión muy diferente, señalando que la evidencia empírica muestra que el acceso a capital es el principal obstáculo para muchos lanzamientos de empresas. En cualquier caso, es evidente que este es un punto en que la literatura aún no ha llegado a un consenso (Henrekson y Stenkula, 2009).

También se desprende de lo visto que existe aún una divergencia en torno a cuán activa debe ser la política de estímulo. Mientras trabajos como Audretsch y Fornielles (2007) o Angelelli y Prats (2005) enfatizan las políticas de intervención por parte del Estado, otros como Hall y Sobell (2006) o Shane (2009) otorgan mayor preponderancia a la reducción de las regulaciones como elemento primordial para impulsar la creación de nuevas empresas.

En cambio autores como Romero Luna y Fernández Serrano (2007) llaman la atención sobre una limitación de las políticas de impulso al emprendedorismo. De acuerdo a su estudio, existe evidencia de que la heterogeneidad regional limita la efectividad de las políticas, si ésta no es debidamente tomada en consideración (Romero Luna y Fernández Serrano, 2007). En la misma línea, Schott y Jensen (2008) señalan que hay evidencia de que el vínculo entre emprendedorismo y políticas de estímulo es mucho más débil en países desarrollados. Según los autores esto podría responder a cierta omisión de características locales relevantes, que llevan a que las fórmulas generales revisadas en este trabajo pierdan efectividad (Schott y Jensen, 2008).

Como sostienen Verdú y Soriano (2008), el modo concreto en el que funciona el proceso de interacción políticas-emprendedorismo-crecimiento no resulta sencillo de detectar con claridad lo cual impide extraer conclusiones de carácter general sobre buenas prácticas (Verdú y Soriano, 2008).

También existen diferencias importantes entre las políticas implementadas en distintos páses, tanto en términos de instrumentos utilizados como del papel desempeñado por los gobiernos y de los resultados alcanzados (Holtz-Eakin, 2000). Shane, por ejemplo, sostiene que la promoción de un gran número de empresas nuevas (start-ups) no es una política pública eficaz. En su trabajo, usando datos para los Estados Unidos y otros países desarrollados,este autor muestra que una importante proporción de start-ups no crea muchos puestos de trabajo o contribuye significativamente al crecimiento económico Recomienda en consecuencia que se financien algunas empresas de alto crecimiento, ya que éstas tendrán probablemente importantes repercusiones económicas (Shane, 2009).

Solimano (2008) llega a conclusiones similares. Al analizar un conjunto de 129 países, encuentra una correlación negativa (aunque débil) entre la proporción de pequeñas y medianas empresas (PYME) en el empleo y el producto y la proporción de la clase media (Solimano, 2008).

Otros estudios como Acs y Amorós (2008) encuentran que la competitividad y el producto interno bruto (PIB) per cápita se correlacionan negativamente con las tasas de emprendimiento en América Latina. Afirman que la competitividad en América Latina no se ha orientado hacia la innovación y el emprendimiento (Acs y Amorós, 2008).

Frente a las opiniones contrapuestas y la falta de consenso teórico en la academia, el estudio de casos específicos de aplicación pareciera ser una aproximación metodológica particularmente adecuada a contemplar en el diseño de políticas de emprendedorismo (Doloreux, 2004; Fuchs y Shapira, 2005).

A la luz de los resultados, podemos afirmar que si bien existen visiones que defienden las más diversas posturas en torno a la aplicación e implementación de políticas de impulso al emprendedorismo, las mismas no han cesado con el devenir de los años. Esto es, aunque 
pudiera cuestionarse su efectividad en términos de fomento a la innovación, generación de empleo o crecimiento y desarrollo económico, la evidencia empírica nos demuestra que las apuestas en este tipo de políticas tienen plena vigencia presente y pasada.

Por supuesto, la vigencia de estos debates se debe a la falta de evidencia empírica contundente que avale unas $\mathrm{u}$ otras posturas. Sin embargo, muchos avances se han realizado con el fin de cuantificar la variable emprendedora en las economías. A continuación describiremos las principales herramientas para la medición y cuantificación del emprendedorismo y sus limitaciones. Con posterioridad, en la última sección brindaremos algunos datos sobre el estado actual del mismo.

\section{Herramientas para la medición del emprendedorismo}

Un elemento central para el éxito de toda política pública de estímulo al emprendedorismo es el cuidadoso seguimiento del avance de los resultados. La fase de monitoreo y evaluación de las políticas requiere necesariamente de la disponibilidad de indicadores con los que seguir la evolución de los resultados (Hidalgo et al., 2014; Angelelli y Prats, 2005). Adicionalmente, el desarrollo de indicadores cuantificables es relevante a la hora de buscar relaciones causales entre el nivel de emprendedorismo de un país o región y determinados indicadores de desempeño económico, como el crecimiento del producto o la generación de empleo.

En ese sentido, un primer enfoque es el uso de variables binarias como, por ejemplo, éxito/no éxito de una nueva empresa o autoempleo/empleo (Bianchi y Biffignandi, 2012). Una limitación de esta aproximación es que dificulta el seguimiento de la dinámica del emprendedorismo, ya que las variables binarias, aunque de fácil construcción, no permiten reflejar cuestiones de escala, que pueden ser particularmente relevantes a la hora de juzgar el desempeño de una política pública orientada a estimular el emprendedorismo.

Otra alternativa mencionada por los autores es la del uso de indicadores estimados de manera indirecta. El fundamento de este enfoque radica en la relación entre la producción observada y los insumos -no observados- utilizando como vínculo una función de producción estimada. La construcción de estos modelos permitiría, al menos desde el punto de vista teórico, estimar los determinantes de la producción a partir de los resultados observados, y establecer comparaciones en el tiempo y entre países (Bianchi y Biffignandi, cit).

El atractivo de este tipo de métodos radica en la posibilidad de elaborar indicadores de bajo costo -construidos a partir de información disponible- y de actualización periódica, dos elementos especialmente atractivos desde el punto de vista de la evaluación de políticas públicas. Sin embargo, los métodos de esta naturaleza, por la necesidad de realizar fuertes supuestos paramétricos, limitan su verdadera utilidad, en especial como instrumento para la toma de decisiones.

Otra línea de medición indirecta del emprendedorismo se basa en su estimación a partir de características individuales. Estudios como Caliendo y Kritikos (2007) y Pretheeba (2014) utilizan modelos econométricos para estimar una propensión al emprendedorismo a partir de características individuales, como habilidades, conocimientos y actitud hacia el emprendedorismo. Este enfoque es interesante, ya que genera herramientas para predecir la probabilidad de éxito de un emprendedor. Incluso, estos modelos predictivos pueden ser una útil herramienta de política económica para maximizar la probabilidad de éxito en la administración de recursos escasos. Sin embargo, el problema de este enfoque es que no provee de instrumentos para el monitoreo directo del impacto de las políticas públicas sobre el emprendedorismo (Caliendo y Kritikos, 2007; Pretheeba, 2014).

Por estos motivos, la mayor parte de los indicadores actualmente utilizados son del tipo cardinal y del tipo directo. En ese sentido, las dos principales referencias a nivel mundial actualmente en materia de elaboración de indicadores de emprendedorismo son OECD-Eurostat Entrepreneurship Indicators Programme (EIP) y Global Entrepreneurship Monitor (GEM, que describiremos en la próxima sección). ${ }^{2}$

El programa EIP está basado en la construcción de indicadores del desempeño emprendedor vinculados a tres aspectos: la creación de firmas, el perfil de empleo, y la generación de riqueza por parte de las firmas (Ahmad y Hoffman 2012). Cada una de esas categorías está comprendida por diversos indicadores, como se detalla en el Esquema 4 a continuación.

\section{Esquema 4 - Indicadores de desempeño emprendedor}

\begin{tabular}{|c|c|c|}
\hline \multicolumn{3}{|c|}{ Entrepreneurial Performance } \\
\hline Firms & Employment & Wealth \\
\hline Employer firm birth rate & High Growth Firm Rate by Employment & $\begin{array}{c}\text { High Growth Firm Rate by } \\
\text { Turnover }\end{array}$ \\
\hline Employer firm death rate & Gazelle Rate by Employment & Gazelle Rate by Turnover \\
\hline Business churn & Ownership rate start-ups & Value-added by young firms \\
\hline Net business population growth & Ownership rate business population & $\begin{array}{c}\text { Productivity contribution, young } \\
\text { firms }\end{array}$ \\
\hline Survival rate, 3 and 5 years & Employment, 3 and 5 year old firms & $\begin{array}{c}\text { Innovation Performance, young } \\
\text { or small firms }\end{array}$ \\
\hline Proportion 3 and 5 year survival & Averange firm size after 3 and 5 years & Export Performance, Small firms \\
\hline
\end{tabular}

Fuente: Ahmad y Hoffman (2012)

Los indicadores resaltados dentro de cada categoría del Esquema 4, a su vez, son aquellos considerados nodales para el relevamiento de la actividad emprendedora. El EIP, además, 
provee una metodología de armonización de la información que garantiza que ésta sea comparable a nivel internacional y a lo largo del tiempo.

Otros autores amplían esta descripción. Lunati (2012), por ejemplo, señala que en EIP se viene trabajando en la elaboración de indicadores que cubren tres dimensiones:

a) Desempeño emprendedor. Donde las variables relevadas son las indicadas en el Esquema 4.

b) Determinantes del emprendedorismo. Como marco regulatorio, condiciones de mercado o acceso a fuentes de financiamiento.

c) Impacto social y económico del emprendedorismo. Creación de empleo, crecimiento económico, reducción de la pobreza y formalización de la economía.

Contrariamente, autores como Ahmad y Hoffman (2012) señalan que, dada la naturaleza multifacética del emprendedorismo, no es conveniente limitarse al seguimiento de un único indicador. Por el contrario, postulan el uso de un conjunto de indicadores como el descripto. Esto, sin embargo, no está exento de problemas, ya que la relevancia de cada grupo de indicadores podría variar en función de los objetivos de política. En ese sentido, la utilización simultánea de varios indicadores podría tener como contrapartida la mayor dificultad a la hora de evaluar el resultado de las políticas de estímulo (Ahmad y Hoffman, 2012).

El relevamiento de GEM también cubre una amplia gama de indicadores, y está estructurado en dos partes. Por un lado, se realiza un relevamiento entre la población adulta de los países comprendidos en el estudio. Este relevamiento permite realizar indicadores vinculados con las siguientes dimensiones:

a) Auto-percepción del emprendedorismo: Oportunidades percibidas, capacidades percibidas, miedo al fracaso e intenciones emprendedoras.

b) Actividad: Actividad Total Emprendedora en Etapa Temprana (TEA, por sus siglas en inglés), tasa de propiedad de empresas establecidas y Actividad Empresarial de Empleados (EEA, por sus siglas en inglés)

c) Motivación: Motivación impulsada por la necesidad o el deseo de mejorar. d) Isualdad de género: Razón Mujer/Hombre del TEA y razón de oportunidad Mujer/Hombre.

e) Impacto emprendedor: Expectativas de empleo e innovación.

f) Valores sociales del emprendedorismo: Estatus social de los emprendedores y emprendedorismo como buena elección de carrera.

Este relevamiento es complementado a su vez por la consulta a expertos de cada economía, quienes aportan su visión sobre siete dimensiones del contexto. ${ }^{3}$

Pese a la amplia gama de indicadores relevados por GEM, el más utilizado es el índice TEA, que mide el porcentaje de población adulta a punto de comenzar una empresa o que la haya iniciado en los últimos tres años (Iversen et al., 2008).

Por caso, Justo y coautores (2008) proponen una metodología para la construcción de un índice que mide la propensión al emprendedorismo, estimado a partir de un modelo econométrico que vincula una serie de preguntas formuladas a encuestados y regresadas contra el índice TEA (Justo et al., 2008)

No obstante este último punto, la literatura muestra una creciente inclinación hacia el uso de múltiples indicadores para la medición. La principal ventaja de este enfoque, particularmente relevante desde el punto de vista de las políticas públicas, es que permite contar con información más detallada y desagregada que la que un indicador único o resumido puede aportar.

Esta desagregación de la información es relevante, ya que un índice agregado podría ocultar trayectorias divergentes en diferentes aspectos. Por ejemplo, Bosma y coautores (2000) encontraron en su estudio que la correlación entre los indicadores utilizados iba del 11\% al 44\%, lo que implica una relación nula o muy débil entre las variables (Bosma et al. 2000). Este punto puede explicar por qué no siempre se ha encontrado evidencia empírica clara a favor de la vinculación entre emprendedorismo y crecimiento económico (ver Naudé, 2013), pese a que este vínculo es ampliamente aceptado desde el punto de vista teórico y de la política económica como venimos afirmando en este trabajo.

En conclusión, se desprende de la literatura disponible que actualmente el enfoque dominante para la medición del emprendedorismo por parte de las políticas públicas se basa en el uso de indicadores multidimensionales como los propuestos por EIP y GEM. Aunque muchos estudios aún utilizan indicadores agregados, como el índice TEA, o 
indicadores puntuales seleccionados, en general ese enfoque se muestra como incompleto a la hora de monitorear los resultados de políticas públicas concretas. A continuación brindaremos los principales resultados que surgen de los últimos informes de EIP y GEM.

\section{El emprendedorismo en el mundo actual}

En este apartado esbozaremos brevemente la situación actual del emprendedorismo a nivel global y en particular en América Latina. El objetivo de esta sección es caracterizar el emprendedorismo actual y mencionar las recomendaciones de políticas que surgen de lo observado.

Es importante destacar que América Latina ha sido un importante motor de conocimiento y avances en torno al estudio del emprendedorismo y sus políticas públicas de fomento. Diversos autores de la región han escrito abundante bibliografia y fueron a su vez un soporte clave para diseñar e implementar políticas y medidas de fomento en diversos países del continente. Muchos de estos estudios ya han sido presentados en las secciones precedentes como ejemplos que contextualizaron nuestros argumentos. ${ }^{4}$

El informe Entrepreneurship at a Glance 2015 publicado por la OECD (2015) presenta la evolución de los indicadores clave para informar el análisis y la política sobre el emprendedorismo en base a la última información del EIP.

Entre las principales conclusiones del informe podemos destacar:

a) En la mayoría de los países, con la excepción de Alemania, Italia y Finlandia, la creación de nuevas empresas ha seguido una tendencia al alza desde el pico de la crisis. Sin embargo, en muchos países de la zona Euro, la creación de nuevas empresas permanece por debajo de los niveles previos a la crisis.

b) Los indicadores de quiebras de empresas, en cambio, han tenido una tendencia a la baja en la mayoría de los países durante los últimos años, con tasas por debajo de los niveles previos a la crisis en Canadá, Japón, Estados Unidos y Sudáfrica.

\section{Panel 1 - Creación y quiebra de empresas, paises seleccionados, 2007-2014.Tendencia-ciclo, 2007=100} a) Creación de empresas

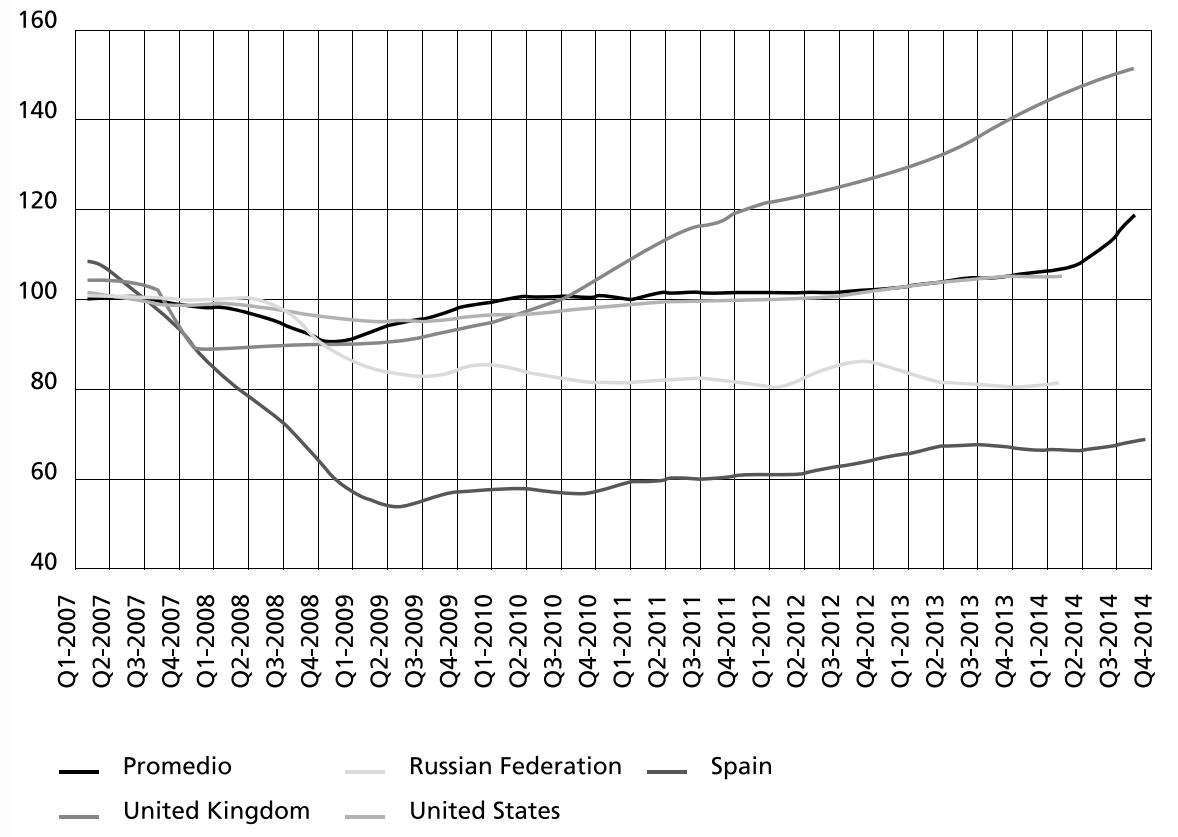

b) Quiebras de empresas

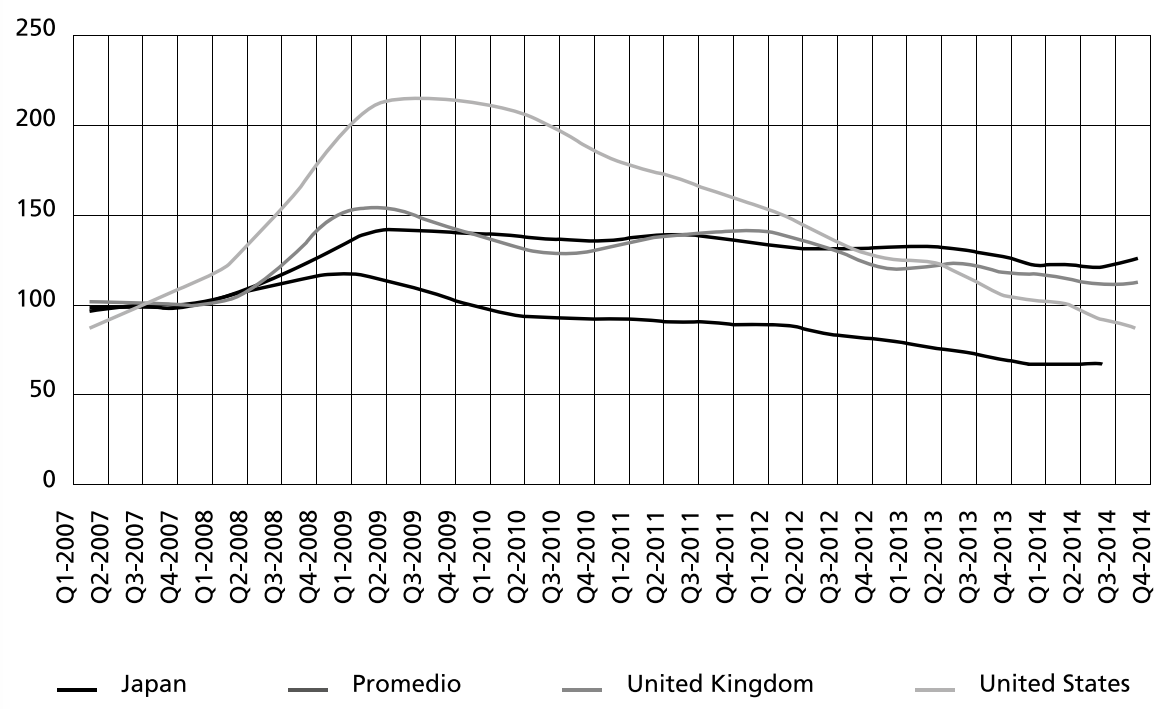

Fuente: elaboración propia en base a OECD Timely Indicators of Entrepreneurship (TIE) Database' 
c) En cuanto a los niveles de empleo por cuenta propia, se observan tendencias variantes y divergentes entre países. Este resultado se explica, en parte, por el diferente impacto que tuvo la crisis sobre el empleo, el ámbito normativo y los mecanismos utilizados para mitigar los efectos negativos de la crisis.

\section{Panel 2 - Tasa de empleo por cuenta propia, países seleccionados, 2007-2015}

Tendencia-ciclo, 2007=100
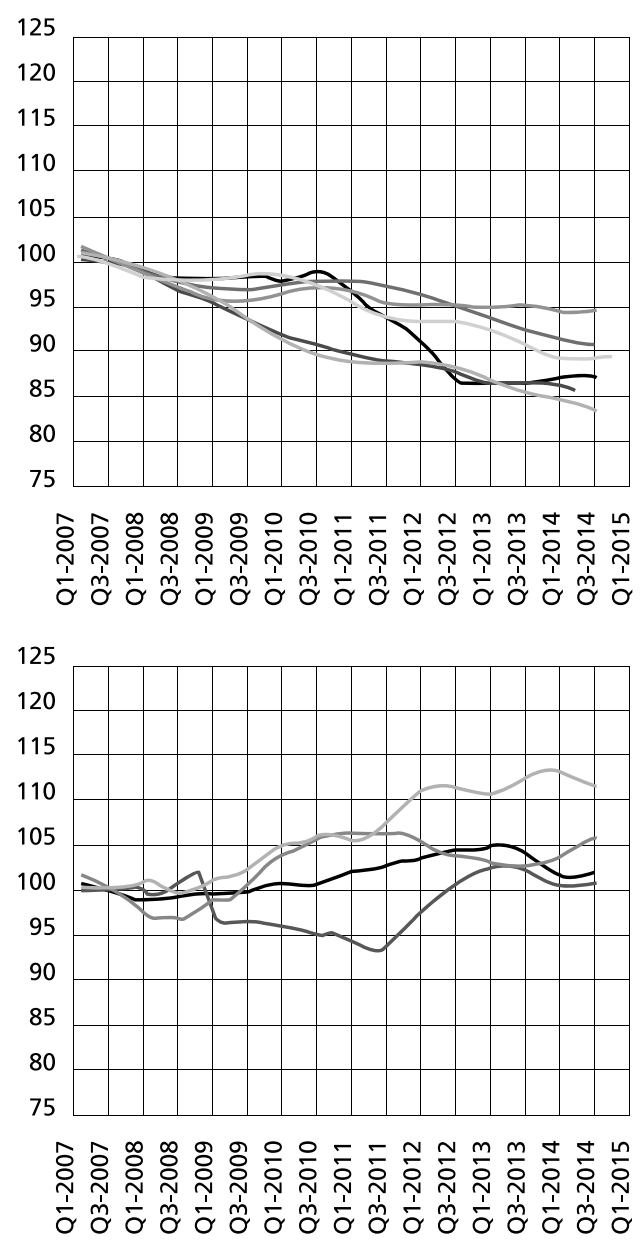

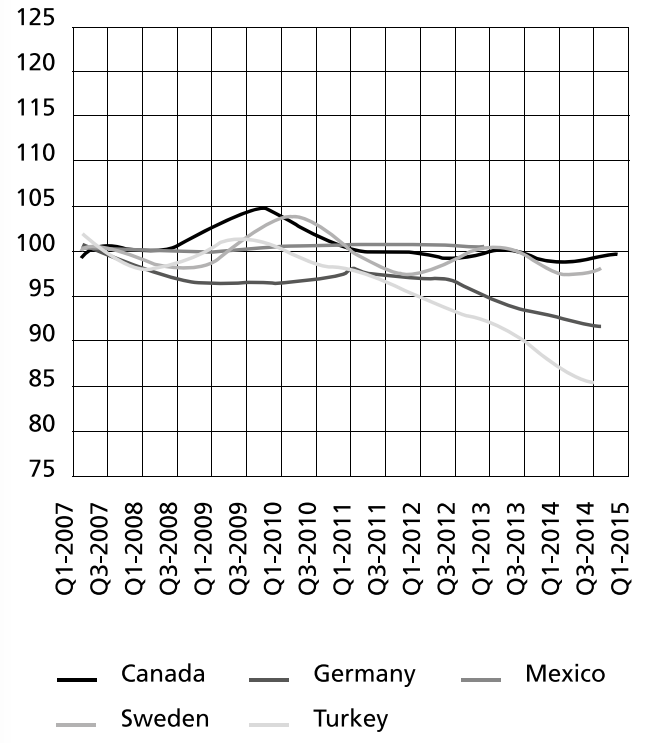

Fuente: OECD (2015)

d) Entre 2008 y 2012 se observa una caída importante en el número de empresas y puestos de trabajo en la industria manufacturera para la mayoría de los países de la OECD. El sector servicios, por otra parte, es quién continua impulsando la creación de nuevos negocios. En todos los países, las empresas de alto crecimiento son más frecuentes en el sector servicios que en el resto de la economía, excepto en Brasil, Canadá, Letonia y Nueva Zelanda, donde el mayor porcentaje de empresas de alto crecimiento está en el sector de la construcción.

e) Las tasas de start-up, aunque siguen altas, cayeron en la mayoría de países en el año 2012, último año del que hay datos comparables a nivel internacional. Más de la mitad de los start-ups fracasan en los primeros cinco años, con tasas de supervivencia de empresas que van desde menos de un quinto en Lituania a cerca de dos tercios en Suecia.

f) Las empresas jóvenes constituyen un canal importante para mejorar la productividad de la eco- 
nomía a través de la innovación y la destrucción creativa. En 2012, estas empresas emplearon entre el $4 \%$ y el $12 \%$ del total de trabajadores en la mayoría de los países. Sin embargo, la contribución de las empresas jóvenes al empleo total ha disminuido en comparación con 2008.

g) En cuanto al tamaño de las empresas que componen la economía, se observa que entre el $70 \%$ y el 95\% de las empresas son microempresas, es decir, empresas con menos de diez empleados. En aquellos países donde el número de pequeñas y medianas empresas (PYMEs) aumentó, se observa una caída en el número de empresas grandes, lo que sugiere que el aumento de las PYME puede haber ocurrido, en parte, como resultado de los despidos en las grandes empresas.

Gráfico 1 - Cantidad de empresas por tamaño según el número de empleados (En \% sobre el total de la economía, 2012 o último dato disponible)

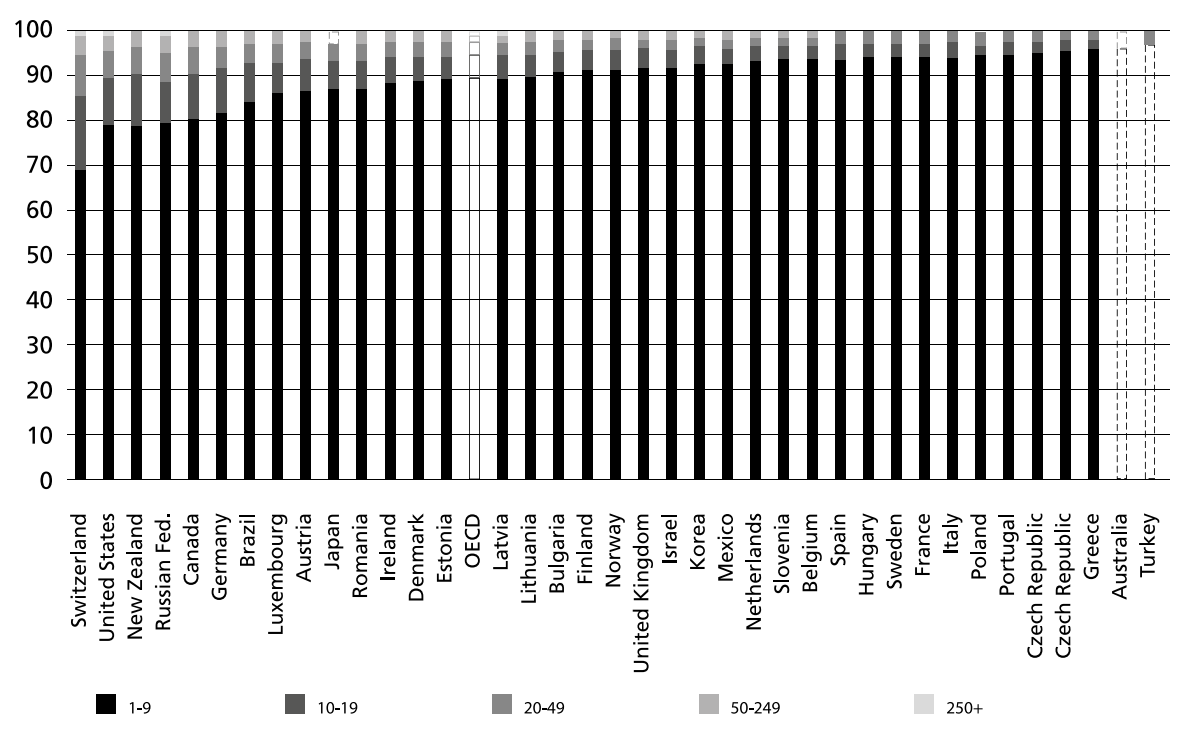

Fuente: OECD (2015)
En resumen, el informe OECD (2015) destaca la presencia de una tendencia positiva en la creación de nuevas empresas, una tendencia decreciente de las quiebras, una menor contribución de las empresas jóvenes en la creación de empleo, una mayor presencia de firmas con alto crecimiento dentro del sector servicios, y una todavía muy importante participación de las PyMEs en el total de las formas que conforman la economía.

En el 2015/2016 Global Report publicado por el GEM (2016), se presentan los resultados de la $17^{\circ}$ encuesta mundial anual de la actividad empresarial a través de múltiples fases de los procesos de negocio; las características, motivaciones y aspiraciones de los empresarios; la actitud que tienen las sociedades hacia esta actividad y la calidad de los ecosistemas empresariales en las diferentes economías. Sesenta y dos economías participaron en la encuesta de 2015, agrupadas de acuerdo a la etapa de desarrollo económico y estructura regional geográfica global. El objetivo de este estudio consiste en informar a académicos, educadores, responsables de políticas y profesionales acerca de la naturaleza multidimensional del emprendedorismo en todo el mundo, el avance del conocimiento y proporcionar orientación para la toma de decisiones que permitan generar las condiciones con las cuales pueda prosperar el espíritu empresarial.

Entre los resultados más relevantes del informe, sobresalen los siguientes, que permiten caracterizar el emprendedorismo actual a nivel global:

a) El grueso del emprendedorismo mundial se ve impulsado más por la existencia de oportunidades que por la necesidad de iniciar un negocio. Esto es, su veta emprendedora florece como una alternativa voluntaria a emprender y no como una decisión forzada por falta de empleo.

b) En las economías fundamentadas en la alta tecnología (donde el factor innovación es indispensable) el $78 \%$ de los emprendedores inician un negocio por una oportunidad. De igual modo, en aquellas basadas en recursos naturales con poca capacidad de transformación o aquellas donde su fortaleza es la manufactura (economías de eficiencia) dicho guarismo se reduce al $69 \%$.

c) A nivel global, el $70 \%$ de los adultos en las 62 economías que participaron del estudio percibe a los emprendedores como individuos de un "estatus elevado" en sus respectivas comunidades. 
d) El 21\% de dichos adultos tienen intención de iniciar un negocio en los próximos tres años.

e) La mayor concentración de emprendedores se encuentran entre las personas de 25 a 44 años de edad, personas en el inicio y mitad de su etapa productiva, en todas las economías (en el rango de 25 a 34 años, uno de cada tres emprendimientos son realizados por jóvenes en este grupo de edad).

f) La mitad de los emprendedores en economías basadas en innovación inició un negocio en el área de tecnologías de información y comunicaciones, finanzas, salud, educación, entre otros. En cambio, aproximadamente la mitad o más de los emprendedores de las economías basadas en recursos y eficiencia operan negocios con menor valor agregado del tipo mayoreo y menudeo.

g) La Tasa promedio de la Actividad Emprendedora Temprana (TEA) tiende a ser más alta en las economías basadas en recursos, disminuyendo en forma correspondiente con los niveles más altos de desarrollo económico (21\% para las economías basadas en recursos, $15 \%$ para las economías basadas en eficiencia, y $8 \%$ en las economías basadas en innovación).

En cuanto a la incidencia de las políticas públicas sobre el emprendedorismo, un resultado interesante para observar es la valoración de las distintas características que conforman el ecosistema empresarial.

Los resultados del informe GEM (2016) muestran a las políticas públicas y a los programas gubernamentales por debajo de la valoración promedio del resto de los ítems que componen el ecosistema empresarial, lo cual refleja la importante necesidad de que los gobiernos mejoren e incrementen las políticas empresariales.

Se advierte en el Gráfico 2 que la menor valoración se registra en los ítems "educación y training empresarial a nivel primario y secundario" y en "impuestos y burocracia".
Gráfico 2 - Valoración del ecosistema empresarial, 2015

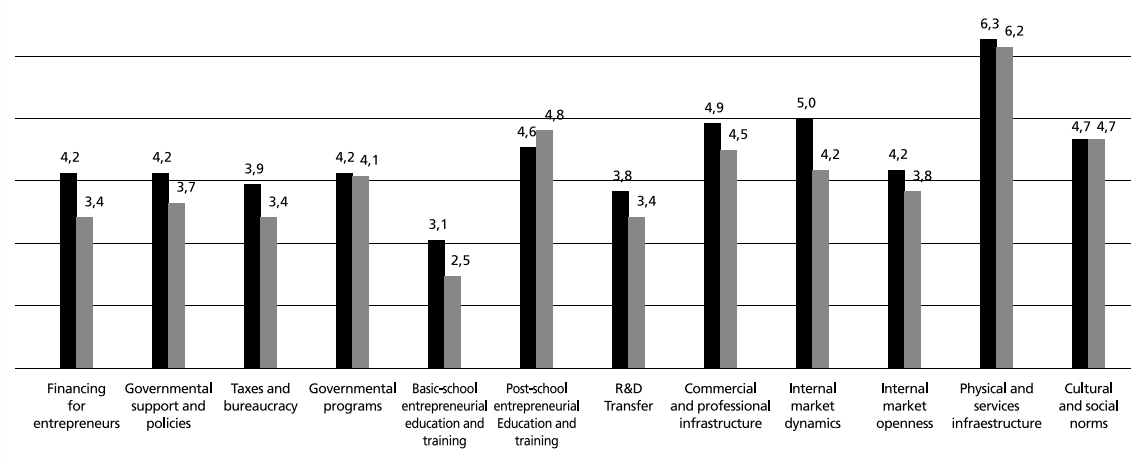

- Promedio mundial $\quad$ Promedio AlyC

Fuente: elaboración propia en base a datos de Global Entrepreneurship Monitor - National Expert Survey Measures, 2015

Promedio ponderado de la puntuación de los expertos: $1=$ =Altamente insuficiente, $9=$ Altamente suficiente

El Gráfico 2 también ilustra las diferencias entre América Latina y el Caribe (LAC, por sus siglas en inglés) y el promedio mundial en relación a la mayoría de los indicadores. La brecha más significativa donde los emprendedores de la región se encuentran por debajo del promedio mundial se corresponde con las posibilidades de financiamiento, la dinámica del mercado interno, la educación y entrenamiento empresarial a nivel de escuela primaria y secundaria, y las políticas públicas. La única categoría donde América Latina y el Caribe alcanza una valoración mayor al promedio mundial es en "Educación empresarial y training a nivel terciario/universitario".

Sin embargo, a pesar de observarse un ambiente de gestación de emprendimientos menos propicio, el emprendedorismo se caracteriza en nuestra región por una importante vitalidad, medida según el número de empresas per cápita (Lederman, D., Messina J., Pienknagura S., y Rigolini J., 2014). Se observa en el Gráfico 3 que la participación de emprendedores y empresas formales en la población, es mayor que en otros países y regiones comparables. 
Gráfico 3 - Relación entre el tipo de empleo y PBI per cápita, 2010. a. Empleadores no agricolas

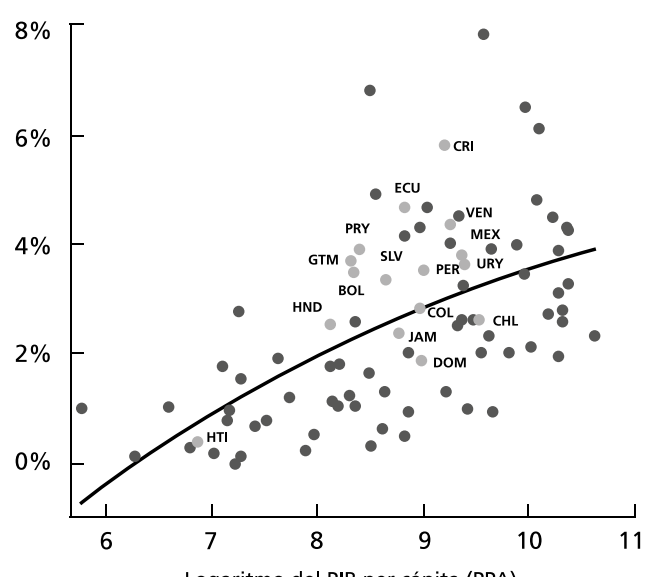

Logaritmo del PIB per cápita (PPA)

- Países de LAC

Paises de fuera de LAC

b. Trabajadores no agrícolas por cuenta propia

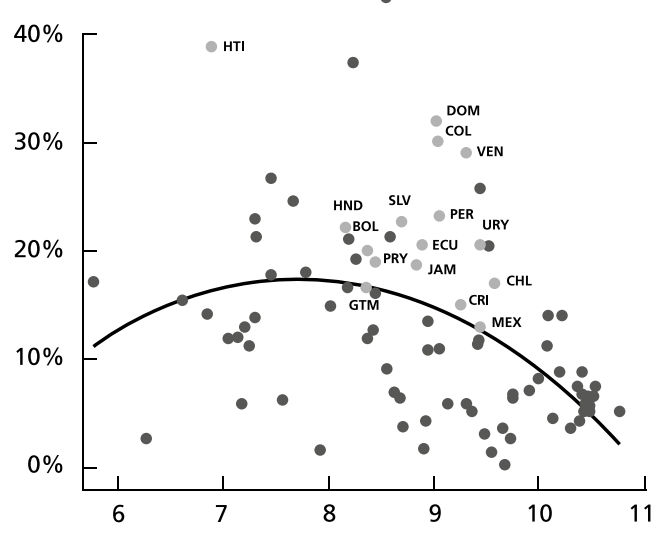

Logaritmo del PIB per cápita (PPA)

- Países de LAC

- Países de fuera de LAC

Fuente: Lederman, D., Messina J., Pienknagura S., y Rigolini J. (2014).

PIB = producto interior bruto. PPA = paridad del poder adquisitivo

De lo dicho se traduce que en América Latina y el Caribe el sector emprendedor es más que un gran sector informal. Sin embargo, la región está claramente aletargada en términos de naturaleza empresarial. Esto es, las mayores empresas crean menos empleo que las empresas más grandes de otras regiones, fenómeno que se refleja desde su nacimiento. Al desarrollarse un emprendimiento en la región las empresas suelen ser más pequeñas (en términos del número de empleados) que en otras regiones con niveles similares de desarrollo y el proceso de crecimiento no alcanza a compensar la brecha inicial en el empleo (Lederman et al., 2014).

Por otro lado, en el Gráfico 4 podemos observar la relación entre la entrada de empresas y el nivel de desarrollo en 129 países. Como era de esperar, la relación entre la entrada de empresas (número de empresas registradas por cada 1.000 personas en edad de trabajar) y el PIB per cápita es positiva. Para el caso de América Latina y el Caribe, las tasas de entrada formal suelen estar por debajo de los valores predichos por los niveles de ingreso per cápita, aunque las diferencias no son siempre grandes y a menudo hay mucha heterogeneidad dentro de la región.

Gráfico 4 - Tasa de entrada de empresas nuevas y PBI per cápita, 2004-2011

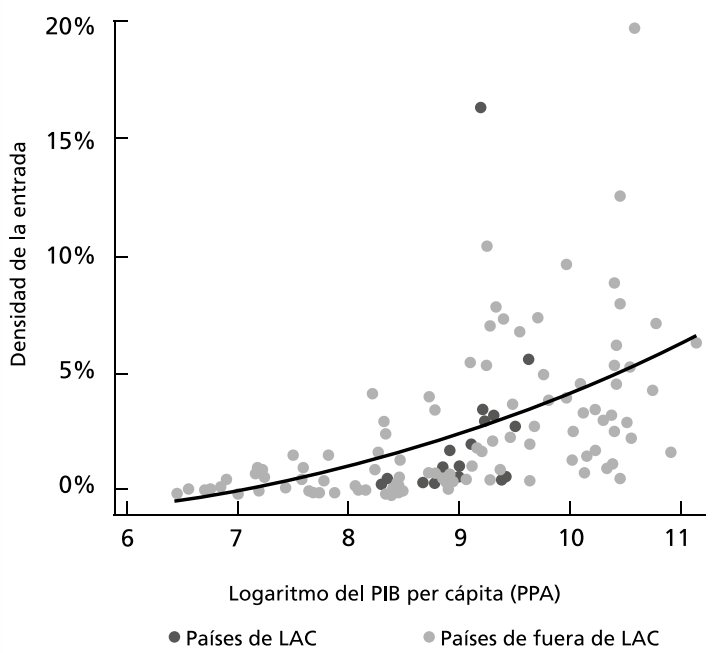

Fuente: Lederman, D., Messina J., Pienknagura S., y Rigolini J. (2014).

Por último, y en concordancia con la sección 5 de nuestro trabajo, el informe GEM (2016) presenta una lista de recomendaciones sobre prácticas apropiadas para fomentar el emprendedorismo a nivel mundial. De acuerdo con los resultados obtenidos, las políticas a implementar deberían ser:

a) Reformar el marco regulador para hacer que las nuevas empresas se registren y operan mediante la reducción de costos y la reducción de la cantidad de regulaciones. 
b) Desarrollar las capacidades de innovación.

c) Introducir los conceptos asociados a los diferentes tipos de actividades empresariales a través de los sistemas de educación a todos los niveles.

d) Ampliar las intervenciones para tratar de base la brecha en la formación de los jóvenes, en particular cuando el desempleo juvenil es un problema.

e) Mejorar la infraestructura de las TIC en áreas más allá de las fronteras de la ciudad.

f) Ofrecer programas específicos para aquellos negocios impulsados por necesidades, dándoles la capacidad de desarrollar más modelos de negocios basados en prácticas de competitividad de precios, contratación y distribución.

g) Enriquecer la disponibilidad y variedad de fuentes de financiamiento.

h) Asegurar que la infraestructura de apoyo a las empresas se construya y se mantenga, proveyendo servicios de formación, asesoramiento y entrenamiento bien diseñados para todas las fases del proceso emprendedor.

i) Trabajar con los medios de comunicación locales para crear conciencia y percepción positiva de la iniciativa empresarial como una posible carrera.

j) Maximizar el potencial sin explotar de las mujeres que, al participar a tasas más bajas que los hombres en una economía, sugieren oportunidades perdidas.

k) Considerar la posibilidad de intervenciones de política en ámbitos relacionados con la jubilación, los impuestos sobre la renta y los beneficios sociales, para direccionar a los grupos de edad donde la gente no tiene particularmente un perfil empresarial en la sociedad.

1) Fomentar el espíritu empresarial en las industrias de alto valor agregado.

\section{Comentarios finales}

En este trabajo se introdujo de modo preliminar la literatura teórica y empírica sobre políticas públicas y emprendedorismo, El objetivo general fue brindar una perspectiva amplia sobre las políticas públicas como variable de influencia en la iniciativa emprendedora de las distintas economías y su relevancia en términos de desarrollo.

El emprendedor parece tener hace años la atención de los investigadores y hacedores de políticas por varias razones. Entre los principales motivos destacan la generación de empleo, la posibilidad de innovación y la creación de nuevos mercados que impulsen el crecimiento y desarrollo económico. Sin embargo, estos resultados se encuentran ligados a distintos tipos de emprendedores, cada uno con características y perfiles particulares.

El ideal del emprendedor schumpeteriano ha permanecido como referente paradigmático del tema en la literatura. Se exige de él que sea creador de valor, portador de innovación, desarrollador de oportunidades de negocios y que participe en el crecimiento de un país con el crecimiento de su empresa. No obstante, el emprendedor no es un innovador aislado que se esfuerza por elegir correctamente en un inventario de invenciones posibles. Por el contrario, construye un proyecto empresarial apoyándose (según la naturaleza de su proyecto) en redes relacionales, en un contexto económico y en un marco institucional fomentado y modificado por las medidas y políticas públicas vigentes.

En este sentido, las políticas públicas de impulso al emprendedorismo cobran una importancia fundamental para moldear ese contexto externo que, finalmente, ayudará a despertar, estimular o potenciar las características internas (muchas veces dormidas) en los emprendedores de una población. La forma y el diseño de dichas políticas serán las que determinen qué tipo de emprendedor será motivado o inhibido en una sociedad.

Los canales que determinan tanto la cualidad emprendedora como su relación causal con el devenir económico son extensos. Su cuantificación no es sencilla y ha alimentado arduos debates en torno a la efectividad y prácticas adecuadas para implementar una política pública en pos del emprendedorismo. Más allá de la falta de consenso o la amplitud del tópico, la promesa del emprendedor como agente clave del desarrollo ha llevado a que los intentos de estímulo no cesen. Por todos estos motivos, no se puede desconocer la importancia del emprededorismo como dinamizador de la economía, como alternativa de 
desarrollo social y como fuente de trabajo y de innovación tecnológica.

Como corolario general de nuestro trabajo, resaltamos que resulta imperioso y necesario que desde el Estado se sigan generando políticas que comprometan de manera sostenible esfuerzos de los sectores público y privado para generar y mantener procesos vigorosos de emprendimiento. Estos esfuerzos, muy probablemente, no serán directamente visibles en términos de resultados a corto plazo por diversos motivos. Algunos de ellos pueden ser la falta de una convicción clara de los beneficios del emprendedorismo, la dificultad que implica la variedad de actores que se deben incorporar y los recursos que se deben comprometer en el proceso.

De cualquier modo, los esfuerzos para fomentar el emprendedorismo con base en la implementación de políticas públicas, integrales, amplias y coordinadas, poseen vastas razones teóricas para justificar su razón de ser. En términos de agendas pendientes, el principal desafio que presenta la relación emprendedorismo y políticas públicas pareciera ser, a la fecha, la suma de evidencia empírica fehaciente, verificable y comparable, que justifique las intervenciones públicas pasadas así como las futuras.
${ }^{1}$ El origen de la palabra viene del vocablo en lengua alemana Unter (tomador) y Nehmer (bajo), con lo cual tendríamos la imagen de alguien que toma algo desde la base, que hace emerger (Liouville, 2002).

Sin embargo, a nivel regional y con foco en los países emergentes, es necesario señalar dos importantes antecedentes con fuentes de datos sobre este topico. Estos son los documentos Entrepreneurship in Emerging Economis" (Kantis, Is da y Konon 2002) y Developing Entrepreneurship: Experience in Latin America and Worldwide (Kantis, Moori Koening, y Angelelli 2005).

${ }^{3}$ A saber, calidad de las políticas públicas, educación emprendedora, regulación de los mercados, acceso al financiamiento, normas sociales y culturales, infraestructura fisica y transferencia de I+D (GEM, 2015).

${ }^{4}$ No obstante, vale la pena destacar los aportes ya expuestos de enfoque y autores regionales como fueron los de Hugo Kantis (2002; 2005; 2010; 2012 y 2016), Pablo Angelelli (Angelelli y Prats, 2005), José Anchorena y Lucas Rinconi (2012), Rogerio Studart (Studart y Suaznabar 2004). A su vez, aquellos inherentes a casos espećficos de la región, como los de México (Lecuona Valenzuela, 2009), Chile (Nopo y Valenzuela, 2007),
Colombia (Tarapuez Chamorro, Osorio Ceballos y Botero Villa, 2013), Uruguay (Dana, 1997), Argentina (Kantis, Postigo, Federico y Tamborini, 2002; Bekerman, Wiñazky y Moncaut, 2014), y Ecuador (Arteaga y Lasio, 2009; Ordeñana y Villa, 2012).

5El promedio incluye sólo los páses con datos disponibles (Creación de firmas: Noruega, Portugal, Rusia, España, Suecia, Reino Unido, Estados Unidos, Australia, Belgica, Dinamarca, Finlandia, Alemania. Italia, Fran-

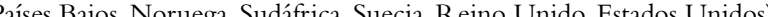

${ }^{6}$ Cada punto representa el promedio entre 2004 y 2011. La curva representa valores cuadráticos ajustados. 


\section{Referencias bibliográficas}

Acs, Z. J., Szerb, L., y Autio, E. (2016) "The global entrepreneurship and development index". En Global Entrepreneurship and Development Index 2015. Zurich: Springer International Publishing: 11-31.

Acs, Z. J., y Amorós, J. E. (2008) "Entrepreneurship and competitiveness dynamics in Latin America”. Small Business Economics, 31(3), 305-322.

Acs, Z., Åstebro, T., Audretsch, D., y Robinson, D. T. (2016) "Public policy to promote entrepreneurship: a call to arms”. Small Business Economics, 47(1), 35-51.

Aghion, P., Akcigit, U., y Howitt, P. (2013) What do we learn from Schumpeterian growth theory? Washington DC: National Bureau of Economic Research, Working Paper 18824.

Ahmad, N. y Hoffman, A. (2012) "A framework for addressing and measuring entrepreneurship”, en Entrepreneurship determinants: culture and capabilities. Eurostat Statistics Books.

Albornoz, M. (2009) "Desarrollo y políticas públicas en ciencia y tecnología en América Latina". RIPS. Revista de Investigaciones Políticas y Sociológicas, 8(1):65.

Amorós, J., y Cristi, O. (2010) Poverty, human development and entrepreneurship. The dynamics of entrepreneurship:Theory and evidence. Manuscrito inédito.

Anchorena, J., y Ronconi, L. (2012) "Entrepreneurship, Entrepreneurial Values, and Public Policy in Argentina”. En E. Lora \& F. Castellani, eds., Entrepreneurship in Latin America. A Stepup the Social Ladder?. Washington DC: IADB: 105-147.

Angelelli, P., y Prats, J. (2005) Fomento de la actividad emprendedora en América Latina y el Caribe Sugerencias para la formulación de proyectos. Washinfgton, DC: Inter-American Development Bank.

Anlló, G. y F. Peirano (2005) Una mirada a los sistemas nacionales de innovación en el Mercosur: análisis y reflexiones a partir de los casos de Argentina y Uruguay. Oficina de la CEPAL en Buenos Aires.

Arellano, J. R. (2016) "La importancia del contexto en el diseño de política social". Revista Perspectivas de Políticas Públicas, No 8:13-26.

Arrow, K. (1962) "Economic welfare and the allocation of resources for invention". En J. Lerner \& S. Stern, eds., The rate and direction of inventive activity: Economic and social factors. Princeton, NJ: Princeton University Press, pp. 609-626.
Asheim, B. T., y Coenen, L. (2005) "Knowledge bases and regional innovation systems: Comparing Nordic clusters". Research policy, 34(8), 1173-1190.

Åstebro, T. B., y Tåg, J. (2015). Entrepreneurship and Job Creation. IFM Working Paper No. 1059.

Åstebro, T., Braunerhjelm, P., y Broström, A. (2013) "Does academic entrepreneurship pay?”. Industrial and Corporate Change, 22(1): 281-311.

Audretsch, D. B. (2003) "Entrepreneurship policy and the strategic management of places". En D.M. Hardt, ed., The emergence of entrepreneurship policy: Governance, start-ups, and growth in the US knowledge economy. Cambridge UK: Cambridge University Press, pp. 20-38.

Audretsch, D. B., Grilo, I., y Thurik, A. R. (2007) "Explaining entrepreneurship and the role of policy: a framework". En D.B. Audretsch et al. eds., The handbook of research on entrepreneurship policy. Northampton, Ma: Edward Elgar Publishing, pp. 1-17.

Audretsch, D. B., y Lehmann, E. E. (2005) "Does the knowledge spillover theory of entrepreneurship hold for regions?”. Research Policy, 34(8), 1191-1202.

Audretsch, D. B., y Thurik, R. (2004) "A model of the entrepreneurial economy". International Journal of Entrepreneurship Education, 2, 143-166.

Audretsch, D., y Fornielles, M. R. C. (2007) "La política industrial actual: conocimiento e innovación empresarial”. Economía industrial, (363), 33-46.

Baumol, W. J. (1990) "Entrepreneurship: Productive, Unproductive and Destructive". Journal of Political Economy, vol. 98 No. 5 (1):893-921.

Baumol, W.J. (1986) "Entrepreneurship and a Century of Growth". Journal of Business Venturing, 1(2), pp. 141-145.

Baumol, W.J. (1993) "Formal entrepreneurship theory in economics: Existence and Bounds". Journal of Business Venturing, vol. 8, nº 3, pp. 197-210.

Bekerman, M., Wiñazky, M., y Moncaut, N. (2014) "La inserción internacional de las empresas PyMEs y los consorcios de exportación en la Argentina. Fortalezas y asignaturas pendientes". Revista Perspectivas de Políticas Públicas, No. 7:43-75.

Belso, J. (2004) “Tasa óptima de empresarialidad y desarrollo económico. Evidencias para el caso español”. Estudios de economía, Vol 2, N³1; 207-225. 
Beugelsdijk, S., y Noorderhaven, N. (2004) "Entrepreneurial attitude and economic growth: A cross-section of 54 regions". The Annals of Regional Science, 38(2), 199-218.

Bianchi, A., y Biffignandi, S. (2012) "A new index of entrepreneurship measure". Journal of Marketing Development and Competitiveness, 6(4), 1-16.

Bosma, N.; van Praag, M. y de Wit, G. (2000) Determinants of successful entrepreneurship. SCALES Research Report 0002/E.

Bratkovic, T., Antoncic, B., y Ruzzier, M. (2009) "Strategic utilization of entrepreneur's resource-based social capital and small firm growth". Journal of Management y Organization, 15(4), 486-499.

Caliendo, M., y Kritikos, A. S. (2008) "Is Entrepreneurial Success Predictable? An Ex-Ante Analysis of the Character-Based Approach”. Kyklos, 61(2), 189-214.

Callejón, M. (2009) “La economía emprendedora de David Audretsch”. Investigaciones regionales: Journal of Regional Research, (15), 47-54.

Chabaud, D., y Ngijol, J. (2004) "La reconnaissance des opportunités de marché par l'entrepreneur: ¿faut-il changer de perspective?”. In Conférence AIMS. https://core ac.uk/download/pdf/646507/pdf

Chirinos, Y. (2013) "Emprendimiento Sostenible como Política de Estado". Memorias VII Jornadas nacionales y IV internacionales de investigación de la URBE. Maracaibo. Venezuela Disponible en: http://www. urbe. edu/portal-biblioteca/basesdedatos-urbe/ponencia/. Consulta realizada el 2.6.17.

Dana, L.P. (1997) "A contrast of Argentina and Uruguay: The Effects of government policy on entrepreneurship". Journal of Small Business Management, vol. 35, n 2, pp. 99-104.

Di Meglio, F. (2016) "Tendencias recientes de las políticas de vinculación científicotecnológicas dirigidas a las universidades argentinas". Revista Perspectivas de Políticas Públicas, No. 11:65-92.

Djankov, S., La Porta, R., Lopez-de-Silanes, F., y Shleifer, A. (2002) "The regulation of entry". Quarterly journal of Economics 117 (1):1-37.

Doloreux, D. (2004) "Regional innovation systems in Canada: a comparative study". Regional studies, 38 (5): 479-492.
Duckett, J. (2001) "Bureaucrats in business, Chinese-style: The lessons of market reform and state entrepreneurialism in the People's Republic of China". World Development, 29(1), 23-37.

Etzkowitz, H., Webster, A., y Healey, P., eds. (1998) Capitalizing knowledge: New intersections of industry and academia. Albany, NY: Suny Press.

Ferri, P. J., Deakins, D., y Whittam, G. (2009) "The measurement of social capital in the entrepreneurial context". Journal of Enterprising Communities: People and Places in the Global Economy, 3 (2):138-151.

Fuchs, G., y Shapira, P. (2005) Rethinking regional innovation and change: Path dependency or regional breakthrough (Vol. 30). Springer Science y Business Media.

Fujita, N. (2007) Myrdal's theory of cumulative causation. Evolutionary and Institutional Economics Review, 3(2), 275-284.

GEM (2016) “2015/2016 Global Report”. Global Entrepreneurship Monitor.

Gómez, H. J., y Mitchell, D. (2014) Innovación y emprendimiento en Colombia-Balance, perspectivas y recomendaciones de política: 2014-2018. Bogotá: FEDESARROLLO.

Guerrero, R. C., y Luna, M. (1997). Gobierno, academia y empresas en México: hacia una nueva configuración de relaciones. Ciudad de México: Plaza y Valdés.

Hall, J. C., y Sobel, R. S. (2006) "Public Policy and Entrepreneurship" (Technical Report, 06-0717). Center for Applied Economics, University of Kansas.

Henderson, J. (2002) "Building the rural economy with high-growth entrepreneurs". Economic Review-Federal Reserve Bank of Kansas City, 87(3), 45.

Henrekson, M. y Stenkula, M. (2009) Entrepreneurship and public policy. IFN Working Paper No. 804.

Hidalgo, G.; Kamiya, M. y Reyes, M. (2014) Emprendimientos dinámicos en América Latina. Avances en prácticas y políticas, Serie Políticas Públicas y Transformación Productiva No. 16/2014, CAF

Holtz-Eakin, D. (2000) "Public policy toward entrepreneurship". Small Business Economics, 15(4), 283-291. 
Howells, J. (2005) "Innovation and regional economic development: A matter of perspective?”. Research policy, 34(8), 1220-1234.

Iversen, J.; Jorgensen, R. y Malchow-Moller, N. (2008) "Defining and measuring entrepreneurship". Foundations and Trends in Entrepreneurship, Vol. 4, No. 1, pp. 1-63.

Justo, R., De Castro, J. O., y Maydeu-Olivares, A. (2008) "Indicators of entrepreneurship activity: Some methodological contributions". International Journal of Entrepreneurship and Small Business, 6(4), 604-621.

Kantis, H. (2004) Desarrollo emprendedor. América Latina y la experiencia internacional. Washington, DC: Banco Interamericano de Desarrollo, FUNDES Internacional.

Kantis, H. (2010) Aportes para el diseño de políticas integrales de desarrollo emprendedor en América Latina. Washington D.C.: Banco Interamericano de Desarrollo.

Kantis, H., Angelelli, P., y Koenig,V. M. (2005) "Developing Entrepreneurship:Latin America and Worldwide Experience”. En P.Angelelli, H. Kantis yV. Moori Koenig, eds., Developing entrepreneurship: Experience in Latin America and Worldwide. Washington DC: IADB, pp. 75-88.

Kantis, H., Federico, J., y Trajtenberg, L. A. (2012) Entrepreneurship, Economic Mobility, and Entrepreneurial Propensity: A Regional View Based on the Analysis of Selected Latin American Countries. InterAmerican Development Bank Working Paper Series 315.

Kantis, H., Ishida, M., y Komori, M. (2002) Empresarialidad en economías emergentes: Creación y desarrollo de nuevas empresas en América Latina y el Este de Asia. Washington, D.C., Banco Interamericano de Desarrollo.

Kantis, H., Postigo, S., Federico, J., Y Tamborini, M. F. (2002) "The emergence of university graduate entrepreneurs: What makes the different? Empirical evidences from a research in Argentina". En RENT XVI Conference, Barcelona.

Kantis, H., y S. Drucaroff. (2009) Corporate Entrepreneurship. Washington, DC: InterAmerican Development Bank

Keuschnigg, C., y Nielsen, S. B. (2006) "Public Policy, Start-up Entrepreneurship and the Market for Venture Capital". En S. Parker, ed., The Life Cycle of Entrepreneurial Ventures. New York: Springer Science+Bisiness Media Inc.:227-257.

Kirzner, I. (1973) Competition and entrepreneurship. Chicago, IL: University of Chicago Press.
Kirzner, I. (1986) "El Empresario". En J. Huerta de Soto (Comp.). Lecturas de Economía Política, 1. Madrid: Universidad del Rey Juan Carlos. Descargar de file:///C:/Users/ Usuario/Downloads/El\%20empresario\%20de\%20Israel\%20M\%20Kirzner.pd

Klepper, S. (2015) Experimental Capitalism: The Nanoeconomics of American High-Tech Industries. Princeton, NJ: Princeton University Press.

Klofsten, M., y Jones-Evans, D. (2000) "Comparing academic entrepreneurship in Europe-the case of Sweden and Ireland”. Small Business Economics, 14(4), 299-309.

Kreft, S. F., y Sobel, R. S. (2005) "Public policy, entrepreneurship, and economic freedom". Cato Journal. 25 (3): 595-616.

Lecuona Valenzuela, R. (2009) El financiamiento a las Pymes en México: La experiencia reciente. Economía unam, 6(17), 69-91

Lederman, D., Messina, J., Pienknagura, S., y Rigolini, J. (2014) El Emprendimiento en America Latina: Muchas Empresas y Poca Innovación. Washington D.C.: The World Bank.

Leibenstein, H. (1968) "Entrepreneurship and development". The American Economic Review, 58(2), 72-83.

Li, H., de Zubielqui, G. C., y O'Connor, A. (2015) "Entrepreneurial networking capacity of cluster firms: a social network perspective on how shared resources enhance firm performance”. Small Business Economics, 45(3), 523-541.

Liouville, J. (2002) "La fonction d'entrepreneur: Schumpeter revisité". Actes du 2ème congrès de l'Académie de l'Entrepreneuriat "Entrepeneuriat et dynamique des sociétés» Bordeaux.

Litan, R., Baumol, W., y Schramm, C. J. (2008) Good capitalism, bad capitalism, and the economics of growth and prosperity. New Haven, Ct. Yale University Press.

Lugo, J. E. B., y Espina, M. I. (2014) "Factores Determinantes para el Desarrollo de la Actividad Emprendedora: Un Estudio Correlacional”. Esic Market Economics and Business Journal 45 (1):161-174.

Lunati, M. (2012) “Developing entrepreneurship indicators", en Entrepreneurship determinants: culture and capabilities. Bruselas: Unión Europea, Eurostat Statistics Books. 
Lundvall, B. Å. (1992) "User-producer relationships, national systems of innovation and internationalization”. En B. Å Lundvall, ed., National systems of innovation:Towards a theory of innovation and interactive learning. London: Frances Pinter Publishers Ltd., pp. 45-67.

Mansfield, E. (1991) "Social returns from R\&D: Findings, methods and limitations" Research-Technology Management, 34(6), 24-27.

Martín, M. Á. G., y Picazo, M. T. M. (2008) “Emprendedores y objetivos de política económica”. Información Comercial Española, ICE: Revista de economía, (841), 29-40

Martínez, D. (2016) Políticas Activas de Mercado de Trabajo para generar empleo y mejorar la calidad de los empleos en América Latina. Cepal: Santiago de Chile.

Minniti, M. (1999) "Entrepreneurial activity and economic growth". Global Business and Economics Review, 1(1), 31-42.

Myrdal, G., (1957) Economic theory and under-developed regions. London: Duckworth.

Naudé, W. (2013) "Entrepreneurship and economic development: Theory, evidence and policy". Evidence and Policy. IZA Discussion Paper, (7507).

Núñez, M. C., y Hernández, R. F. (2015) "Emprendedorismo en Costa Rica: estancamiento en la transición a la innovación”. Economía y Sociedad, 20(48), 1-19.

Ñopo, H. y P. Valenzuela (2007) "Becoming an Entrepreneur". Washington, D.C. IADB Research Department Working Paper series, \# 605.

Observatorio Nacional del Emprendedor (2015). Análisis transversal del gasto en políticas de apoyo a emprendedores. Observatorio Nacional del Emprendedor. Descargar de www.one.inadem.gob.mx

OECD (2015) Entrepreneurship at a Glance 2015. Paris: OECD Publishing. DO dx.doi.org/10.1787/entrepreneur aag-2015-en

Ordeñana, X., y Villa, R. (2012) "Mobility and Entrepreneurship in Ecuador:A Pseudo-Panel Approach". Latin American Journal of Economics 51 (2) 307-341.

Pages, E. R., Freedman, D., y Von Bargen, P. (2003) "Entrepreneurship as a state and local economic development strategy". Entrepreneurship Policy, 240-259.

Pignatta, M. A. (2016) “Monitoreo y evaluación de políticas públicas en América Latina: brechas por cerrar". Revista Perspectivas de Políticas Públicas, N 8: 49-69.
Pratheeba, P. (2014) "Predicting entrepreneurial intention among business and engineering students in Sri Lanka”. Ruhuna Journal of Management and Finance, 1(1) 13-26.

Ravier, A. (2006) "Hacia un estudio comparativo de las teorías económicas defendidas por Joseph Schumpeter y Ludwig von Mises”. Revista Académica Libertas, XIII (44) 253-329.

Reynolds, P. D., Carter, N. M., Gartner, W. B., y Greene, P. G. (2004) "The prevalence of nascent entrepreneurs in the United States: Evidence from the panel study of entrepreneurial dynamics". Small business economics, 23(4), 263-284.

Reynolds, P. D., Hay, M., y Camp, S. M. (1999) Global Entrepreneurship Monitor Kansas City, Mo.: Kauffman Center for Entrepreneurial Leadership, p. 3.

Rikap, C. (2012) "La vinculación de la universidad con el sector productivo. Transferencia tecnológica: technological transference”. Ecos de Economía, 16(34), 127-149.

Robb, A. M., \& Robinson, D. T. (2012) "The capital structure decisions of new firms”. Review of Financial Studies 27 (1) 153-179.

Rodrik, D. (2008) One economics, many recipes: globalization, institutions, and economic growth. Princeton, N.J.: Princeton University Press.

Romero Luna, I., y Fernández Serrano, J. (2007) “Un análisis de la heterogeneidad empresarial en la Unión Europea. Implicaciones para la política europea de fomento empresarial". Ekonomiaz, 3(66), 350-371.

Schneider, B. R., y Wolfson, L. (1999) "Las relaciones entre el Estado y las empresas y sus consecuencias para el desarrollo: una revisión de la literatura reciente”. Desarrollo Económico, 153:45-75.

Schött, T. (2011) "Networks and Entrepreneurs in Latin America: A Comparison among Countries". Unpublished manuscript, University of Southern Denmark, Odense.

Schott, T. y Jensen, K, W. (2008) "The coupling between entrepreneurship and public policy: tight in developed countries but loose in developing countries." Estudios de Economía, vol 35, No. 2: 195-214.

Shane, S. (2009) "Why encouraging more people to become entrepreneurs is bad public policy”. Small business economics, 33(2), 141-149.

Solimano, A. (2008). The middle class and the development process. Santiago de Chile: CEPAL. 
Stam, E., Suddle, K., Hessels, J., y Van Stel, A. J. (2007) "High growth entrepreneurs, public policies and economic growth”. Jena Economic Research Paper, (2007-019), 08-02.

Stevenson, L., y Lundstrom, A. (2002) "Entrepreneurship policy-making: Frameworks, approaches and performance measures". International Council for Small and Medium Sized Enterprises. Washington DC: The World Bank.

Stevenson, L., y Lundström, A. (2007) "Dressing the emperor: the fabric of entrepreneurship policy”. En D. Audretsch, I. Grilo \& A.R. Thurik, eds., Handbook of research on entrepreneurship polic. Northampton, Mass: Edward Elgar Publishing Inc., pp. 94-129.

Studart, R., y Suaznabar, C. (2004) "El acceso al financiamiento, un reto para la creación de empresas dinámicas". En H. Kantis, ed., Desarrollo Emprendedor. America Latina y la experiencia internacional. Washington, D.C. BID-Fundes:111-125.

Tarapuez Chamorro, E., Osorio Ceballos, H., y Botero Villa, J. J. (2013) "Política de emprendimiento en Colombia, 2002-2010”. Estudios gerenciales, 29(128), 274-283.

Verdú, F. M., y Soriano, D. R. (2008) "Rol de la política industrial en el 'entrepreneurship' ¿ cambia la tendencia?”.Información Comercial Española, ICE: Revista de economía, (841), 85-96.

Winchester, L. (2016) Politicas públicas: formulación y evaluación. Santiago de Chile: ILPES/CEPAL.

Winter, S. G. (2006) "Toward a neo-Schumpeterian theory of the firm". Industrial and Corporate Change, 15(1), 125-141.

Zacharakis, A., Shepherd, D. A., y Bygrave, W. D. (2000) Global Entrepreneurship Monitor: National Entrepreneurship Assessment, United States of America: 2000 Executive Report. Kauffman Center for Entrepreneurial Leadership at the Ewing Marion Kauffman Foundation.

Zurbriggen, C., y Lago, M. G. (2014) "Innovación y co-creación. Nuevos desafios para las políticas públicas". Revista de Gestión Pública, 3(2), 329-361.

Cómo citar este artículo

Carballo, Ignacio E., Carlos M. Belloni, Martín López Amorós y Eduardo

L. Fracchia (2017) "Emprendedorismo y políticas públicas. Una introducción a la

literatura". Revista Perspectivas de Políticas Públicas vol. 7 No 13.

\section{El proceso de construcción de las necesidades en las políticas habitacionales. Un modelo teórico - metodológico para su análisis desde una perspectiva interpretativa}

Shaping housing needs in public policies. A theoretical - methodological model from an interpretive perspective.

Venettia Romagnoli Arquitecta, Magister en Gestión del Ambiente, el Paisaje y el Patrimonio Docente de la Facultad de ArqLACSO y Urbanismo de la Universidad Nacional del Nordeste (FAU- UNNE). Investigadora Adiunta UNNE-CONICE. Investigadora Adjunta UNNE-CON

Fecha de recepción: 28.4.17

Fecha de aceptación 6.8.17

\section{Resumen}

El trabajo que aquí se presenta fue desarrollado en el marco de la tesis doctoral recientemente finalizada, denominada "¿Qué vivienda necesitan los pobres? Un estudio sobre la configuración de las necesidades en las políticas habitacionales vigentes a partir del caso del AMGR (Chaco, Argentina)", que se dedicó a analizar el proceso de configuración de las necesidades habitacionales en las políticas públicas, para identificar sus diferentes momentos, los actores involucrados, sus intereses, roles, estrategias e incidencia en la politización, interpretación e implementación de dichas necesidades. Este artículo se dedica al desarrollo del modelo teórico - metodológico construido para el análisis del fenómeno mencionado. 